\title{
REC-WP 03/2009
}

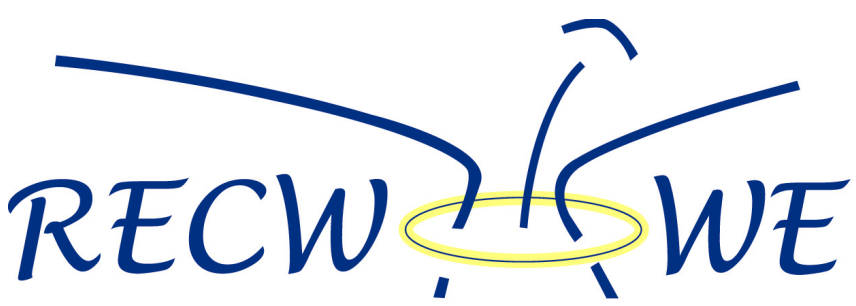

Working Papers on the Reconciliation of Work and Welfare in Europe

\section{Applying Sens Capabilities Framework to Work Family Balance within a European Context:}

\section{Theoretical and Empirical Challenges}

\author{
Barbara Hobson \\ Susanne Fahlén
}



Barbara Hobson and Susanne Fahlén

\section{Applying Sens Capabilities Framework to Work Family Balance within a European Context: Theoretical and Empirical Challenges}

\section{REC-WP 03/2009}

Working Papers on the Reconciliation of Work and Welfare in Europe RECWOWE Publication, Dissemination and Dialogue Centre, Edinburgh

(C) 2009 by the author(s)

The Working Papers on the Reconciliation of Work and Welfare in Europe series seeks to promote the diffusion of research and research integration activities taking place within the network and being produced by other researchers working on issues of work and welfare in Europe.

Working papers are published either within the framework of a series of closed calls, which follow the different stages in the life-cycle of the network's activities, or as part of an open call, which aims to privilege both research focussed on cross-national comparative analysis of the various tensions between work and welfare and research focussed on the role of the European level in addressing these tensions.

All papers are peer-reviewed.

The Working Papers on the Reconciliation of Work and Welfare in Europe are published online by the Publication, Dissemination and Dialogue Centre (PUDIAC) of RECWOWE. They can be downloaded at

http://www.socialpolicy.ed.ac.uk/recwowepudiac/working papers/

RECWOWE / PUDIAC on the internet: http://www.socialpolicy.ed.ac.uk/recwowepudiac 


\section{About the authors}

Susanne Fahlén is an advanced doctoral student in sociology with a multidisciplinary background in cultural anthropology and demography. She is member of the RECWOWE strand devoted to tensions within employment and family reconciliation. Currently, she is working on two RECWOWE projects; one focusing on WFB and capabilities and the other on the impact of labor force attachment and work hours for women's childbearing intentions and realized fertility. A recent related publication, co-authored with Barbara Hobson, is titled "Two Scenarios for European Fathers: Adversity and Risk? Opportunities and Agency for a Work Family Balance" The Annals of the American Academy of Political and Social Science, 2009: 64 .

Barbara Hobson is a full professor in Sociology at Stockholm University. She is a coordinator for the Family, Work and Welfare Regimes strand in RECWOWE, and an editor and founder of Social Politics (OUP) She has published numerous books and articles on gender and welfare states concerning citizenship and welfare regimes, men and social politics and social movements and gender and diversity. Relevant recent publications to this Working Paper include: "Two Scenarios for European Fathers: Adversity and Risk? Opportunities and Agency for a Work Family Balance" The Annals of the American Academy of Political and Social Science, 2009: 64 (with Susanne Fahlén), "Men and Worklife Balance: Which men, which policies and which institutional contexts?" In Children, Family Policies and Welfare State Change, edited by Jane Lewis, Edward Elgar, 2006 (with A. Z. Duvander, and K Halldén), "Birthstrikes? Agency and capabilities in the reconciliation of employment and family" Journal of Marriage and Family Review 2006: 39:1 (with Liva Oláh), "Making Men into Fathers: Men, Masculinities and the Social Politics of Fatherbood" Cambridge University Press, 2002. 


\begin{abstract}
This state of the art has two specific aims: One is to present the dominant theories and identify weaknesses in theories that have sought to explain the processes surrounding the division of time and paid/unpaid work in families, specifically addressing models of agency and work family balance. The second and main purpose of this paper is to provide a theoretical framework and set of indicators for analyzing agency and work family balance in a complex and multi-layered universe of constraints and possibilities, of rights and capabilities to exercise them. This framework derives its inspiration from Amartya Sen's framework on capabilities and agency freedom and much of the paper will be devoted to discussing the framework and the theoretical and empirical challenges that it poses for comparative welfare state research with a multi-level approach, that integrates the individual/household level, supra-national and national policy level and firm/work organizational level. The paper takes up theoretical and empirical challenges that Sen's framework poses for welfare state research: How are the tensions and contradictions in WFB balance policy both within and beyond the nation state reflected in agency inequalities? How do institutional settings shape not only individual practices but also the perception of one's entitlement to make a claim, the conversion of rights into claims? How do we design research models that capture the multiple sites of claims making for WFB: household; work organization and the state? We present several models of capabilities incorporating a mutli-level framework of individual, institutional and societal resources. The assumptions in this model are applied to data in the 2004 wave of the European Social Survey.
\end{abstract}

\title{
Keywords
}

Agency, Amartya Sen, gender, welfare regimes, work, family 


\section{Introduction ${ }^{1}$}

This state of the art has two specific aims: The main purpose is paper is to provide a theoretical framework and set of indicators for analyzing agency and work family balance in a complex and multi-layered universe of constraints and possibilities, of rights and capabilities to exercise them. ${ }^{2}$ The framework derives its inspiration from Amartya Sen's framework on capabilities and agency freedom and much of the paper will be devoted to discussing the framework and the theoretical and empirical challenges that it poses for comparative welfare state research with a multi-level approach, that integrates the individual/household level, supra-national and national policy level and firm/work organizational level. A second aim is to present the dominant theories and identify weaknesses in theories that have sought to explain the processes surrounding the division of time and paid/unpaid work in families, specifically we are addressing models of agency and work family balance.

\section{Scope of the paper}

Given the focus on this state of the art on agency and capabilities in the context of Work Family Balance (hereafter WFB), we have limited the scope of the state of the art to those studies that specifically concern theoretical boundaries of agency. Therefore, this is not a mapping of studies of macro/micro level indices for assessing gender inequalities from a work family balance perspective, and there are numerous high quality studies in this area (see the works of Gornick and Meyers 2003, Gauthier 2004, Blossfield and Drobnic 2001). There is also a vast time budget research literature that will not be covered in this state of the art, though time is a crucial dimension for theories of agency and WFB. Our focus will be on frameworks and theories that directly confront issues of agency, that is, ways of explaining the organization of time, the division of paid and unpaid work, and the decisions and strategies for the organization of care for family members.

Considering the central purpose of this paper, to incorporate a capabilities/agency perspective into the analyses of WFB, we do not intend to construct a generalized normative model for all aspects of gender and agency inequalities and well being that can be applied across all societies so that the focal point is Europe. Moreover, dimensions such as bodily integrity, health, political empowerment are not specified in the models that we present, though these are dimensions that shape and can be shaped by WFB.

The paper consists of four parts: (1) at the outset of the paper, we discuss work family balance as a European discourse in light of cross-currents in EU strategies. Then we present the rationale for the capabilities and agency paradigm to capture the multi-level dimensions in WFB research (2) The following section engages with three broad categories of theories of agency that seek to explain gendered variations in WFB: Preference Theories, Bargaining Models; and the Household Strategies Concept. (3) The third section presents a series of models of capabilities and agency that extends and adapts Sen's notion of the capability set, which integrates individual resources with 
institutional and societal/cultural resources (Sen 1992, Sen 2003; Browne et al. 2004). (4) In the final section, we apply the capabilities framework to data collected in the module of the fourth wave of the European Social Survey (ESS) on WFB. This analysis provides the basis for operationalizing Sen's framework in cognitive models of agency and developing survey instruments tailored to the capabilities approach. Here we take up theoretical and empirical challenges that Sen's framework poses for welfare state research: How do institutional settings shape not only individual practices but also the perception of one's entitlement to make a claim, the conversion of rights into claims? How are the processes both within and beyond the nation state reflected in growing agency inequalities for some and capabilities for others?

\section{Work Family Balance: A discursive terrain and Conceptual Framework}

Reconciling work and family responsibilities emerged as discursive refrain in EU discourse within the context of promoting policies for women to enter paid work. Motivating these strategies for the dual earning family were concerns about efficiency, productivity; competitiveness, which were central in the debates; gender equality was in the foreground (Stragegki 2004: Lewis 2004).

Though the EU has prioritized reconciliation of work and employment and advocated greater sharing of care and household responsibilities (EC 2003; Hantrais 2000; Deven and Moss 2002), by and large, the strategies have been geared toward increasing women's labour force participation, rather than increasing men's carework.

The EU policy that directly addresses WFB, the Parental Leave Directive, gave all parents, mothers and fathers, the rights to leave after a child was born. By making parental leave gender-neutral (in contrast to maternity leaves), the EU Directive $(96 / 34)$ gave men in several countries their first opportunity to use their parental rights to take time off from their employment for fathering. Still, in most countries this is not a social right to care. Whereas maternity benefit levels range between 60 to 100 percent of previous income in most countries (based upon Gauthier and Bortnik 2001 estimates of the proportion of pay replacement for a women industrial worker $)^{3}$, parental leave in most EU countries is a low flat rate benefit, in some countries it is a means-tested benefit, and no legislated paid benefit in a few others. The exceptions are some of the Scandinavian countries with parental leave benefits between 80 and 100 percent of previous wage. Ferrarini (2003), using estimates based on the proportion of leave benefits with the net earnings of an average industrial workers wage in 2000, shows that for nearly all European men that amounts to about 20 percent of their income; again the exceptions are Finland, Norway and Sweden. Of course, some fathers (as well as mothers) gain benefits through specific collective bargaining agreements or special policies in firms. Still, undeniably, the majority of European men are limited in their ability to exercise their rights to parental leave, given the minimal levels of replacement for men's income and the negative effect that it would have on the household economy. 
Two other directives, Part Time Work and Limits to Working Times directives are also relevant to WFB, creating capabilities for more time for family life.

The Directive on Part Time Work $(97 / 81)^{4}$ does not establish the right to request reduced hours, though it "recommends" that employers facilitate part time work at all levels and that member states adapt their social security systems to accommodate part time work (Fagan 2006). Among EU policymakers, flexibility in working time is viewed as strategy to promote work life balance for parents, but it also is a strategy that offers employers the opportunity to adjust workers hours to productivity. There are marked differences across EU countries in the extent and form in the rights of employees to reduce hours. ${ }^{5}$ Moreover there are few measures that specifically encourage men to take up this option. The rights to reduce hours have been most pertinent to mothers' reconciliation of employment and family, and many studies note the double-edged nature of part time work, allowing many women to have jobs who otherwise would not have been able to combine employment with raising children. Yet this option affects women's earnings, and lifetime earnings (Fagan 2004).

Considering actual working hours and WFB, the European Union's WorkingTime Directive (93/104/EC) has established a 48-hour upper-limit to weekly hours and most member states establish a more stringent limit on weekly hours (McCann 2004). Although the incidence of long working hours seems to be plateauing or declining in Europe (Parent-Thirion et al. 2007), it is actually increasing in the accession EU countries (Hobson et al. 2006). Nevertheless although in the EU 15 member states, there is a greater regulation of contractual working times, men's actual working times, non-contractual overtime in the evenings and on weekends is not declining as seen in the high proportions of fathers who are working more than a 40 hour work week (Hobson et al. 2006: Hobson and Fahlén 2009). ${ }^{6}$

In the 1990s, reflecting the growing interest in the incompatibility of long working time regimes with family and particularly fathering, another discursive frame gained salience in EU documents, work life balance. As a discursive frame, it is more inclusive than that of reconciling work and family in two important respects: (1) it casts work and family life as a quality of life issue, so that WFB encompasses both more leisure time as well as time to spend with family and time to care for them. (2) Whereas implicit in the frame of reconciling work and family was the expectation that women were the reconcilers, work family balance has sought to profile policy in a more gender neutral casing. It embraces a more holistic set of policies that takes into account men as parents: flexibility in work times, time banks for accumulating time for being with a new family; parental leave schemes that are targeted for fathers (daddy days and daddy months). On the symbolic level, the phrase worklife balance or work family balance highlights the fact that participation in different spheres of life beyond employment is in itself a value (not a responsibility). 
In contrast to work life balance, which carries with it an implicit hyphen between work and life that assumes one's work cannot be part of one's life; that they are competing spheres, work family balance retains the value in having a balanced life, as well as participation in the spheres of work and family as a standard for well being. ${ }^{7}$ In recognizing that being able to achieve a balance in one's life involves participation in family and employment, we emphasize the interactions in families: what fathers do affect what mothers do and vice versa, so that policies addressing fatherhood and men's work time and caring time for their children cannot be divorced from policies aimed at mother's reconciliation of employment with family life. We have opted to use the concept of work family balance (WFB), though Work life balance is often used interchangeably with it in EU documents and European studies or work and family life.

\section{Work Family Balance and Sen's Capabilities Approach}

In both research and policy analysis, WFB has been used as a normative framework for analyzing variations across different institutional settings in terms of men's and women's ability to participate in spheres of work and family life. Families with two earners reduce the sense of risk and insecurity made apparent by growing pressures from global economic processes and retrenched welfare states. The growing concern about poverty of single mothers across European societies has made visible the risks for women who are full time housewives (Hobson 1994; Bradshaw et al. 1996). Some recent studies also suggest that WFB policies can have a positive effect on fertility rates (Hobson and Oláh 2006; McDonald 2000; EspingAndersen 1999).

WFB in the EU policy context and in EU discourse is presented as producing optimal strategies leading to economic efficiency, gender equality, and child well being (EC 2002, 2003). ${ }^{8}$ It is important to keep in mind that the capabilities framework is by definition one that seeks to enhance the potential of individuals to secure a quality of life; hence individual well being is an end in itself, and economic efficiency and productivity or increasing birthrates may or may not support WFB goals. WFB goals for productivity and competitiveness often sit often sit uncomfortably with social goals (Carson 2004), reflecting the disjuncture between two work life scenarios: the embodied worker expected to develop strategies to reconcile having and caring for children with employment and the disembodied worker assumed to be unencumbered by care responsibilities who is expected to devote all his/her energies to the one's job. Work demands have become intensified in globalized economies so that flexibility and adaptability in the new economy often removes the boundaries between home and work (Perrons et al. 2006). Workers are expected to be on call and accessible all the time, unable to 'switch off' during family and leisure time (Fagan et al. 2006; Duvendak and Stavenuiter 2004).

These tensions are part of broader conflicts around work and welfare in European societies and within families, the competing EU frames of the market and the social (Carson 2004). In individual families, they are built into the mosaic of lived 
lives, often experienced as work family imbalance: the lack of hours in the day to complete what is expected at work and the demands and desire for more family time, referred to as the time squeeze (Fagan et al. 2006).

Theories of agency and capabilities have the potential to capture these tensions and contradictions; between expectations, norms and practices, between rights and the ability to exercise them. Sen's theory of Agency freedom provides the theoretical space to confront these complexities: (1) by embedding individual agency into specific institutional settings, (2) by acknowledging differences in situated agency.(variations in resources and means), and (3) by constructing a theory of agency that recognizes that agency involves subjective states of efficacy, which he defines as agency freedom, an individual's real freedom to choose, which goes beyond inequalities in resources, but whether you can convert them into who you are and what you do (Sen 1992: 2003)

WFB is a framework in current research projects on household strategies (Wallace 2002); gender and employment (Fagan 2004; Van der Lippe and Peters 2007) and analyses of comparative welfare state institutions and policy regimes (Hobson et al. 2006; Hobson and Oláh 2006).

WFB has been applied empirically to describe the trade off between time and money in choosing employment versus care (Crompton and Brockman 2006). However, beyond the most general everyday usage of being able to combine having and caring for a family with employment, how can use it analytically. There is no consensus on what would constitute a measure of balance between work and family life and what the gendered assumptions are. Furthermore there is no agreement on which policies should best overcome men's care deficit and women's discrimination and lack of integration in employment, which can be both a result of their actual care responsibilities or assumed responsibility for doing the carework (statistical discrimination). Beyond the most general everyday usage of being able to combine having and caring for a family with employment, we ask how we can use WFB analytically.

When coupled with capabilities and agency, WFB becomes a quality of life issue for considering "substantive freedom to choose the life one has reason to value" (Sen 1999, p. 74). The capabilities approach enables us to develop other measures of well being beyond the material and earnings (Iversen 2003; Nussbaum and Sen 2003), what Sen refers to as an evaluative space for achieving a better quality of life (Sen 1992; Browne et al. 2004) These outcomes, or as Sen would call them, "functionings", can include basic forms of well being, such as having health care and education, shelter, and employment. They also embrace other areas of social life, such as taking part in the community and having respect (Sen 1992). In this study, we include being able to have a family and be an active parent in family life as a functioning (an outcome to be achieved) in most advanced industrialized societies. 


\section{Agency Theories and WFB}

WFB has been used descriptively in analyses of outcomes on how individuals in families balance time and money (Bunting 2004). From an agency perspective Work family balance/imbalance is interpreted as an expression of preferences or utility (Hakim 2003; Becker 1991). In the following section, we present some of key theories that have dominated the research on agency and family decisions around work and family life. We focus on the internal critiques and in addition, view them from a capabilities perspective.

\section{Utility and Preference theories}

As much has been written about Becker's Household Economy model (1991), we will not devote much space to explaining the theory. The basic thesis is that families seek to optimize their skills and human capital and thus specialize: women are better at caring (domestic capital) and men get the best economic returns on their human capital. "Wage rates are lower for women at least partly because they invest less than men in market human capital, while the productivity of household time is presumably greater for women because they invest more than men in domestic capital" (Becker 1991, p. 26).

There have been many critiques of the assumptions in this model. Numerous studies show that individuals in families do not necessary pool incomes (Pahl 1989; Lundberg and Pollack 1996)) so for women and children this may not result in optimal utility (Folbre 1994, 1995). Most relevant to our analyses of WFB are (1) that the household economy model fails to consider the importance of institutional settings in shaping work/ family options and preferences (Folbre 1994, 1995); and (2) that preferences are not static but shaped by shifts in economic opportunities and cultural values. The latter is obvious when considering the dramatic changes around women's human capital investments and returns over the last decades. Not to be ignored in considering the specialization of roles in the household economy model is the weakening of the male breadwinner wage alongside its concomitant assumption of secure and tenured employment for life. Given the instability in jobs and temporary and flexible employment, women's sole investment in domestic capital within the family carries with it a high degree of risk.

Looking beyond Becker, we see a revival of preference theory from another economist, Catherine Hakim. We devote a significant amount space to discussing her theory because it relates to some of the key dimensions in gender, WFB and capabilities. Unlike Becker, her notion of preferences does not confirm to rational choice assumptions, but rather take as their starting point à priori cultural values and lifestyles. According to Hakim (2003, 2000), these lifestyle choices tend to be linked to differences in human capital investments, though not always. In effect the causation goes in the other direction from the Becker model. Values and lifestyles drive employment orientation, rather than lifestyles and WFB choices reflect or respond to employment opportunities and human capital investments. Hakim herself 
claims that her model is not a theory, but a thesis derived from survey data. Nevertheless, it is obvious that the "thesis" reflects theories based upon gender, culture and static preferences.

Hakim divides women's orientation into three broad categories, rooted in an assumption that women's work orientations are set early on and remain stable so over the life course. The categories are family oriented, work committed and adaptive (Hakim; 2000; 2003). Hakim maintains that between 10-30 percent of women see family life and children as their main priorities throughout their lives. They prefer not to work and are not responsive to employment policies. In addition, they have different values, including caring, sharing, and cohesion than competition, market values. Another category, referred to as work-oriented women, also comprising of about 10-30 percent, are presented as achievement oriented, driven by market values of individualism. Though responsive to labour market opportunities; they are not responsive to social policies. The majority of women are cast as adaptive, showed to vary between 40-80 percent - this group seeks a compromise between two conflicting sets of values. They are very responsive to government social policy and employment policy. This diverse group includes women who want to combine work and family, and drifters or those without planned careers. Not surprisingly, Hakim's preference thesis on work orientation has been employed by neoliberal governments to argue against government intervention in WFB (Brennan 2007). There is an irony in this because the largest category of women in her model of work orientation is those who are the most responsive to policy intervention.

The empirical critiques of Hakim underscore the fact that she does not take into account the broader institutional context in which parenting decisions are made and remade over the life course (Ginn et al. 1996; Crompton and Harris 1998, Proctor and Padfield 1999). This research challenges her core theoretical assumption that orientations and commitment to work are longstanding, rooted in cultural values and lifestyle preferences and underscores the fluctuations in women's orientations to work (Ginn et al. 1996). Using longitudinal data sets, Man yee Kan (2007) shows through a presentation of recursive regression models that work orientations can change. Even those who fit Hakim's work oriented group with continuous full time work patterns may leave the labour force. Man yee Kan (2007) concludes that not only does work orientation affect labour market choices, but also labour market choices affect work orientation: Hakim's uni-directional view of employment commitment cannot imagine change. Another study based on semi-structure interviews of both single women and women with young children at two points in time (Proctor and Padfield 1999) reveal that orientation and other aspects of agency are dynamic, only understood by looking at the complexity in the circumstances shaping employment decisions and changes involving life course events. Furthermore, their data demonstrates that even young women with children who defined themselves as homemakers expressed a desire to enter training and education beyond their homemaker role (Proctor and Padfield 1999). Looking over time at career-oriented women, they found respondents who changed their orientation, often responding to changes in circumstance, a loss of job and change in personal 
situation. These highly textured accounts reveal the interplay between capabilities and agency and the constraints and possibilities for women to make choices. Several critical debate articles raise the fundamental question around Hakim's accounts of preferences: whether women's employment choices are rooted in women's identities and interests or if these choices are shaped by the structure of working times and market demands for part time workers (Ginn et al. 1996; Crompton and Harris 1998), that there is a process of positive feedback in these choices (Crompton and Lyonette (2005).

Seen from Sen's framework on capabilities and agency, one could regard the women in Hakim's three categories as adaptive; their strategies or rationalities (Duncan 2005) for reconciling family and employment are shaped by a universe of normative and structure constraints as well as potential individual means and resources (Sen 2003). The same point can be made for fathers. The studies analyzing parental leave in Sweden maintain that father's choices can be understood in terms of adaptive preferences, which reflect norm constraints at the societal level, demands and expectations at the workplace, and economic and social pressures at the household level (Bygren and Duvander 2004; Hobson et al. 2006).

Sen's framework calls into question the unstated assumptions in preference theory and utility models. This aspect of the capability framework addresses a key dimension often ignored in the vast literature on gender and welfare states:? inequalities are not just limited to the market and employment, but also exist in nonmarket settings, and importantly for this study, intra-household inequalities (Iversen 2003; Hobson 1990; Orloff 1993). In the following section, we focus on bargaining models that assume differences in economic resources in families, power and dependency, are driving forces shaping agency inequalities.

\section{Bargaining Models: negotiations over time and money in the household.}

Unlike the utility models, bargaining perspective recognizes that the household is not basically a unit of shared interests and that the "pooled resources" in household income, are not necessarily shared equally. Bargaining models assume that outcomes in bargaining are determined by relative resources: the more resources individuals bring to the family economy, the greater power they have in the negotiations over time and money; this can involve more than just who does the unpaid care work, but decisions on place of residence, who leaves their employment and community to follow their spouse/partner.

Dating back to Nash's model of marriage and intra-household allocation of resources and the bargaining power of two spouses (1953), bargaining models have become a dominant framework for analyzing power and exchange in households (Blood and Wolfe 1969; Blumstein and Schwartz 1991; Hobson 1990; England and Kilbourne 1990; Bittman et al 2003). For example in my study of No Exit No Voice, Hobson made the following assumptions based upon the Albert Hirshman's power resource bargaining model: (1) The more dependent, the weaker the voice;(2) the 
lower earnings potential, the fewer exit possibilities; (3) the weaker the exit possibilities, the weaker the voice.

However over the last years, research has shown that the mechanisms of power in the family operate in less straightforward ways than is predicted by these bargaining models. In Gender trumps Money, Bittman et al. (2003) when comparing the US and Sweden find that consistent with exchange-bargaining theory, women decrease their housework as their earnings increase up to the point where both spouses contribute equally to the household income. In their study, gender trumps money when women earn more; women compensate with a more traditional division of household work (see also Brines 1994). In fact, looking at men's unpaid household work, the author's show that men's household work is unresponsive to changes in which spouse provides how much income. Women can reduce their own hours of unpaid work, but this may not mean that men reduce theirs. ${ }^{10}$ This is consistent with findings in Hobson's research (Hobson 2006; Hobson et al. 2006).

\section{Cultural Norms}

These findings lead us toward a discussion of gendered norms, a key dimension for understanding how families organize paid and unpaid work, time and money. Some empirical research on bargaining models have analyzed the kinds of gendered outcomes in dual earning families discussed above in terms of latent power; how societal norms increase men's agency to prioritize their needs and resist pressures to do more housework and carework. Alternatively women who have internalized these norms are inhibited even from making claims and raising objection. Comparing gender logics in two societies, Sweden and Japan, Takahashi (2003), as expected, finds that Swedish women and their partners share household work more equally, express more egalitarian attitudes than Japanese couples. Japanese high-earning wives in this study were reluctant even to ask their husbands to increase their share of unpaid work. What is surprising in her comparison is that even a significant proportion of Swedish employed women did not feel entitled to make a claim for greater sharing, which reflects latent power processes legitimated by traditional male breadwinner/female carer norms, also operating in society with a longstanding dualearner couple norm.

Agarwal (1997) provides the most extensive analysis of the limits of bargaining models for understanding inequality in households in her analysis of norms and social perceptions, which she claims are not easily quantified as are economic resources, i.e. economic dependency in marriage. These involve basic sets of values over what is work and how it is valued: unpaid housework and carework are considered unskilled (Agarwal 1997): Sen (1990) refers to these undervalued contributions of women in households as a "perceived contribution response".

Furthermore she argues that in contrast to most bargaining models, social norms affect outcomes of bargaining and are in fact part of the bargaining itself. They are most often viewed as exogenous to WFB (Lundberg and Pollack, 1996), but they can 
also be endogenous Folbre 1995, they can constitute a factor to be bargained over. Is care better done by women or by men? In countries with entitlements for men to take care leave this question is no longer uncontested. These kinds of entitlements can result in conflicts within families around claims to care leaves (see Hobson et al 2006) but they can also result in changes in norm construction and new forms of agency for both fathers and mothers.

Having revealed the limits of bargaining theory through an analysis of norms, Agarwal (1997) argues for the importance of looking beyond the household in analyzing bargaining processes in families: the market, community and shared identity in geographical or social communities. In effect she suggests the need for a framework of agency that recognizes the importance of multi-layered context in which decisions are made.

\section{Household strategies}

The household strategies is an agency-centred approach that has been important for underscoring the ways in which that the family is a dynamic institution rather than the passive outcome of policies; that there are different cultures of work and care (Wallace 2002; Pfau-Effinger 2005). According to Claire Wallace, one its main proponents, the household is both a social as well as economic unit that should be studied in terms of norms, cultures and values. However, in focusing on the household as an actor in itself, the household strategies approach does not take into account the situated agency of individuals within families; and their diverse situations and settings that shape agency for work life balance claims and this affects what kinds of entitlements and claims they can make within the family as well as the gendered consequences after family dissolution (Hobson 1994)

To understand family decisions in WFB and agency in the context of WFB, we need to consider how situated agency of individuals (and latent power in families) not only shape what they do, but also their perceptions of what individuals feel entitled to do (Hobson and Oláh 2006; Bygren and Duvander 2006). How do structures impinge on individual perceptions of their sense of entitlement to make a claim in the household? What are the sources of entitlement, including norms and values in the wider society, policies and norms in the workplace, laws and policy discourse on the national and supra-national policy levels? The capabilities approach with its multi-layered approach provides a framework for understanding the contextual factors that shape agency, the subjective states of efficacy to make claims for WFB.

\section{Models of Agency and Capabilities}

As is obvious from the above discussions, the missing piece in the household level theories and models of an agency is the lack of a specified theory incorporating institutional contexts. Nearly two decades of research on welfare regimes - of which RECWOWE has been built - has been engaged by this endeavour. Nearly as much 
time has elapsed since gender and welfare state research began to interrogate the explanatory models that did not include gender outside the formal labour market (for example the importance of services and carework). In these policy regime approaches, institutional settings shape outcomes; collective actors, including workers' parties and women's movements are key variables explaining variations across welfare states (Korpi 1983; Huber and Stephens 2003; Hobson and Lindholm 1997; O'Connor et al. 1999). The clusterings of welfare states reveal how institutional contexts can be enabling for women's labour force and the reconciling of employment with family responsibilities (Esping-Andersen 1990; 1999; Korpi and Palme 1998), but they do not lead us toward a theory of agency that reveals the processes by which individuals convert institutional resources into capabilities.

Korpi (2000) makes the most serious attempt to incorporate a capabilities and agency approach into models of gender inequalities. Applying Sen's notion of agency freedom, Korpi (2000) uses participation in the labour force as the main dimension for analyzing capabilities, as it is the "arena for the major socio-economic processes in modern society". According to Korpi (2000) labour force not only determines the distribution of resources, but also it affects women's self perception, identity and the scope for capabilities and freedom in different spheres of life. He offers a model in which welfare state provisions and institutional contexts that support dual-earning couples are those most likely to reduce gendered agency inequality. However, we need to go further: a capabilities framework applied to gender, work and family necessitates a more complex model. How do institutional resources convert into agency? To develop a capability set for gender equality, one must begin with a model that takes as its point of departure that a capability set is multi-layered including not only laws and specific policies, but also norms and values that are legitimated and reproduced in policy and discourse, a dimension, which is crucial for understanding gender agency inequalities. ${ }^{11}$ Agency inequalities operate in different sites that inhibit or promote the exercise of one's rights and sense of entitlement to make a claim. In our case they include the household and growing awareness of the importance of the workplace (Bygren and Duvander 2006), alongside the policy level. Finally there is growing consensus on the importance of including men's rights and their participation in different spheres of work and care. This involves awareness that what men do (how they organize employment and care) affects women's agency for gender equality. Furthermore, his model does not take into account that jobs in themselves may or may not lead to better quality of life: the social quality of these jobs may be poor in terms of pay and working conditions. Poverty and time poverty of parents seeking to combine employment cannot be divorced from agency freedom. In this study we maintain that WFB is an evaluative space for both gender equality and measure of the capabilities to achieve a quality of life.

WFB research calls for a paradigm that allows for more dynamic models of welfare state change and family fluidity. Path dependency is the core mechanism explaining patterns of institutional development and stratification outcomes in welfare states. It also lays behind the types of logics of gender regimes, that is, the extent to which welfare states weaken or sustain a male breadwinner wage, the basic 
formulation in gender regimes (Esping-Andersen 1990; Korpi and Palme 1998; and Lewis 1997). However in the current period of welfare state change, the scripts appear more fluid, both because of increasing expectations for gender equality in families (McDonald 2000) as well as a growing sense of insecurity and uncertainty in male jobs and declining male wages (Walker et al. 2000). Built into a capabilities approach are the possibilities for different scenarios and alternatives: it asks us to think about what a person can be and do: his/her potential and opportunities to achieve.

\section{Why Sen's framework of Agency and Capabilities?}

Much of the literature on WFB, both case studies and comparative research that suggests not much progress has been made despite the dramatic rises in women's labour force participation and the new proactive polices to increase men's share of carework. Time budget studies show surprisingly little change in the amount of unpaid work in the home that men are doing (Blossfield and Drobnic 2001; Smith 2004).Some research shows that women's hours of unpaid have decreased. It reflects women reducing how many hours they devote to domestic tasks rather than men increasing theirs (Statistics Sweden 2001) or mothers who have substituted the labour of women migrants from Eastern Europe and Asia (Gavanas and Williams 2008). The state of the art research shows that despite new rights for men to care, both in terms of parental leave and weeks/month targeted for fathers have not translated into fathers significant increases in take up rights of parental leave. ${ }^{12}$ Even in the cases of best practice, for example, in Sweden in which over half of fathers are now using some of the parental leave months, their proportion remains at 20 percent. The glass is still half empty, according to the current empirical research (Haas and Hwang 2000; Hobson et al. 2006). Alongside this ostensible stasis in WFB, there is research suggesting more fluidity and dynamic situations that are not reflected in the outcomes or statistics on men's caretaking. ${ }^{13}$ This is not to suggest that the glass half empty account is inaccurate, but rather we see alternative scripts and potential scenarios for change.

1. Sen's capability approach allows for more dynamic models. The capabilities approach allows us develop models for WFB that are multi-dimensional and that capture the agency potentialities for change that reflect what one can aspire to or imagine.

2. Sen's capabilities theory takes a multi-layered approach to agency. His capabilities approach nests individual agency within larger institutional and societal contexts. Lewis notes that the capabilities approach allows us to address care work and the importance of genuine choice to care, which are dependent upon institutional settings and their collective provisions in cash and services (Lewis 2004). Furthermore, his approach recognizes that institutional contexts not only shape access to resources, but also subjective states of efficacy - not only what one does, but the possibilities to be and do. This is the essence of what he identifies as agency freedom (Sen 1992; 2003). 
3. Sen's capabilities framework is context specific. One of the main critiques of Sen's theory of capabilities is that he does not provide a specific set of capabilities, rights, but rather a general framework. This is articulated most fully by (Nussbaum 2003), who maintains that it is imperative to develop a normative model of basic capabilities of social justice that could be applied across societies, a list of conceptions of what we should be doing and being. However, we and others consider Sen's insistence that his capabilities framework be context specific a strength rather than a weakness (Agarwal et al. 2003; Robeyns 2003). It permits us to embed the theory in different types of societies, or geographic, social and political regions (Europe in this study). It allows for a context specific approach in selecting and weighing different functionings (achieved outcomes) in relation to capabilities, a way of analyzing which values are valued (Sen 1992). Sen refers to this process as the comprehensive outcome (1992, p. 151) that encompasses the emergence of values through democratic dialogue. WFB can be seen as example of a value that has become hegemonic in most European societies (see ESS results discussed below in this paper), part of the EU's evaluative space on gender equality and family well being. It has emerged through dialogues on many levels: policy discourse and norm construction, mobilization of actors beneath and above the state; advocated by NGOs, and epistemic communities.

\section{Capabilities and Agency applied to the European Context}

Considering the mainframe of the RECWOWE network, we find examples of how the capabilities approach has been applied in the European context (Salais and Villeneuve 2004). The main thrust in these studies has been on social policies involving jobs and employment considering rules, institutions, and EU and national frameworks that have the potential to enhance the capabilities of collective actors and individuals. For the most part, gender has been on the margins of this enterprise with little attention to the family/household level (Lewis 2004).

The challenge for this research is to develop models that reveal how capabilities on the institutional level are translated and converted into the agency and freedom of individual European citizens to pursue well being. Barnard et al. (2001) and Browne et al. (2004) have taken up this challenge in their analyses of capabilities and rights. These studies maintain that individual capabilities are to some degree a consequence of his/her entitlements. Laws and particularly social rights can enhance capabilities: they are part of an individual's capability set to convert her/his assets and resources into positive outcomes. Using the example of the protections of pregnant women from dismissal from work, Browne et al. (2004) suggest that these laws act in direct and indirect ways as conversion factors to enhance choices; the existence of such laws can motivate women to increase their human capital, knowing that they will be able to retain their jobs after becoming pregnant. Indirectly rights can lead to development of a different ethos or "seed" new norms that can have a destabilizing effect on conventional assumptions about the division of paid and unpaid work and 
overturn employer's discrimination against women workers (Browne et al. 2004; Barnard et al 2001).

In presenting this example, Browne et al. (2004) recognize that not just the existence of rights, but also how they are converted into actual practices is what leads to greater capabilities. Nevertheless, the authors fail to comprehend that equality in capabilities in the case of women's employment, involves conversion factors that are multi-dimensional, and if put into effect would pose radical challenges to gendered norms, workplace organization and culture, and family situations. This is obvious if we consider the fact that protections against pregnancy dismissal have not done much to alter the patterns of gender discrimination in the labour market and inequalities in the family. In fact, the laws/protections against pregnancy dismissal may have a perverse effect of producing other forms of statistical discrimination against women in the labour market, ${ }^{14}$ as it is only maternity leaves that have the full and encompassing protections in EU law, not parental leaves or daddy leaves (Hobson et al. 2006). ${ }^{15}$ To do this challenges us to specify both the different types of resources that individuals have and the conversion processes that result in greater capabilities.

As Browne et al. (2004) affirm, the capability approach provides a dual methodology, two evaluative spaces. One is for analyzing a set of dimensions for the potential of individuals to achieve a quality of life that incorporates WFB (their capability set), ${ }^{16}$ and two is a normative framework for evaluating institutional forms and policies that promote individuals capability to achieve it. Our approach assumes that these two levels are highly interactive and they work in tandem. Institutional forms in themselves do not lead to agency freedom, but they are crucial for converting individual resources into sources of entitlement and agency to make claims. They reduce risk and perceptions of security so they weaken the effect of individual means and resources on one's agency to make claims. Institutional resources can facilitate changing norms in families and workplaces, often influenced by how they are framed in policy discourse. The elegance of Sen's capabilities theoretical framework is that it links macro-level processes with micro-level perceptions of risks and agency and with actual practices, that are reflected in what Sen refers to as the capability set. In the following section, we present a model of capability set that could be applied to the WFB in a European context.

\section{Designing a Capability Set in a European Context}

In the following section, we develop a model of a capability set for WFB that is adapted to the European context. Sen concept of the capability set consists of three categories (1) Individual factors that comprise gender, ethnicity age etc. (2) environmental factors, involve physical surroundings, technological infrastructure, ${ }^{17}$ (3) Societal factors include social norms, legal norms and public policies (gender and ethnic stereotyping). We employ the category of institutional factors instead of environmental factors. 
As Model 1 illustrates, we have modified and adapted Sen's capability set for a WFB research design. Individual resources are fairly straightforward and match Sen's category. As the household is an integral part of WFB, we have built in partner's resources to the model and social and family networks (family and friends support systems are often crucial for many families in which both parents are in paid work: this is suggested in many studies as well as our analyses of ESS data with indicators that show that grandparents and other relatives are sources of daycare for children).

\begin{tabular}{|c|c|c|}
\hline $\begin{array}{l}\text { Individual } \\
\text { Resources }\end{array}$ & $\begin{array}{l}\text { Institutional } \\
\text { Resources }\end{array}$ & $\begin{array}{c}\text { Societal/Community } \\
\text { Resources }\end{array}$ \\
\hline \begin{tabular}{l}
\multicolumn{1}{c}{ Situated Agency } \\
Individual Rcsources \\
gender, ethnicity,age \\
Human capital, \\
Income \\
Partner's resources \\
Social Networks
\end{tabular} & $\begin{array}{l}\text { Welfare Regime } \\
\text { Benefit'services } \\
\text { EUI/Nal } 1 \text { Laws: } \\
\text { Antidiscrimination } \\
\text { Job security, flexibility } \\
\text { Labor Markets } \\
\text { Social quality of jobs } \\
\text { Firm/organizational } \\
\text { culture } \\
\text { Union strength }\end{array}$ & $\begin{array}{l}\text { Norms } \\
\text { Socictal } \\
\text { Community } \\
\text { Family/Friends } \\
\text { Media/ Public Debate } \\
\text { Social Movements/ } \\
\text { mobilizations }\end{array}$ \\
\hline
\end{tabular}

Model 1: A Capability Set of WFB in an European Context

For our purposes, considering WFB in European societies, we employ the category institutional resources rather than environmental factors. These encompass many of the features that reflect different aspects of welfare regimes, such as types of benefits and services that support WFB, such as day care policies, job protection laws, levels of expenditure for welfare benefits and services. Institutional resources in WFB entail features of the labour market that affect the organization of time and the potential for achieving a work family balance. Social qualities of jobs affect time so that unskilled low paying jobs often force individuals to work long hours or work two jobs. Working time regimes (defined as legal and social norms of expected working times by Rubery ,1998; Bruning and Plantenga 1999) can stand in the way of requests for reductions in working time hours, particularly for men. The proportion and access to part time jobs are other dimensions of one's capability set and reflect working time regimes. For example if the norms in women's employment are linked to expectations of their care responsibilities, they are more likely to have working time regimes with short part time hours rather then long part time weekly hours (Plantenga et. al 1999). If short time part time jobs are the rule, this often reflects structural features in the labour market, which suggest another key dimension of 
capabilities and WFB, the social qualities of jobs - whether they are fixed contracts or temporary jobs.

Our innovation in the development of a capability set, is in the third category in the model of societal/community factors. Here we have introduced different levels of norm construction beyond and beneath the societal level. This category takes in community and EU levels and the norms and values at the societal level of family and friendship networks. Moreover, public debates and media campaigns are important venues for norm construction and norm challenges (see Figure 1 above).

\section{Conversion Factors}

How do these resources get translated into agency and capabilities? We know that the law in itself may not lead to changes in practices; that laws may not be exercised. Here what Sen calls conversion factors come into play. From the perspective of WFB, suppose we consider what possible conversion factors or processes operate that enable individuals to convert resources into capabilities. First of all, not just the rights but whether these are social rights are essential for capabilities (Deakin 2003; Browne et. al 2002 ). Parental leave without high compensatory levels is one example. Another conversion factor is how a policy or law is implemented. Job sharing in the Netherlands was a policy that sought to alter WFB as well as encourage women's employment. ${ }^{18}$ But the implementation was weak. It was not a right, but at the discretion of the employer: Most importantly it did reach other areas of agency inequalities; other parts of workplace cultures and gender inequities in pay. Finally flexible work schemes may produce less rather than more agency freedom, when they are designed for the employer to maximize profits rather than promote work family balance. Union strength in itself might not have any effect on in the individual's capabilities for WFB unless there is a commitment from the leadership to support the policy. Union support for WFB issues can take the form of collective agreements, but equally important is a union's ability to put pressure on employers to abide by regulations and law; that is, providing those challenging recalcitrant employers with union backing.

In this preliminary analysis, we assume that conversion factors are embedded in policy regime clusters and agency and capabilities for achieving a work family balance reflected in institutional resources or the lack of them.

\section{Applying the Capabilities Framework to WFB to European Societies}

Using the ESS 2004 wave with the family and employment module, ${ }^{19}$ we analyze agency inequalities for a WFB considering the two key dimensions of time and flexibility in the one's job and workplace organization. We also include data on norms and attitudes on gender equality in employment and in the family, which are important for assessing the gender dimensions of WFB. Here we consider the gap between norms and values for reconciling family and employment and the 
constraints European parents of small children face to achieve WFB, as seen in the working times and work intensity.

In this preliminary analysis, we have selected 10 countries that represent different configurations of welfare regime types ${ }^{20}$ Scandinavian or Dual Earner (Denmark, Finland, Sweden), Liberal or Market-Oriented (UK), Conservative or family welfare regime type (Netherlands, Germany); Conservative-Latin Rim (Spain), ${ }^{21}$ and PostSocialist (Czech Republic, Hungary and Poland). The Post-Socialist countries are a hybrid category leaning more toward the Liberal and Market oriented policy configuration, but these societies also would fit Korpi's dual earner type (Hobson and Oláh 2006). Included in our sample are all individuals between the ages of 20-55 years of age, having some employment or being self employed in the sample year, living in a couple with least one child below 13 years of age living in the household; 1,483 men, 1,005 women.

\section{Attitudes and Norms: Gender, Care and Work life Balance}

Before considering norms surrounding WFB, we want to take up the related questions on gender equality in work and care. A logical place to begin comparisons on attitudes toward WFB is with male breadwinner norms. Here we analyze the responses to five questions; (1) whether men should have priority for jobs when they are scarce, (2) whether women should reduce hours for the sake of the family; (3) whether a person's family should be main priority in life, (4) whether men should take as much responsibility as women for home and children, and (5) whether it is important, when choosing a job, that it allows a combination of work and family life

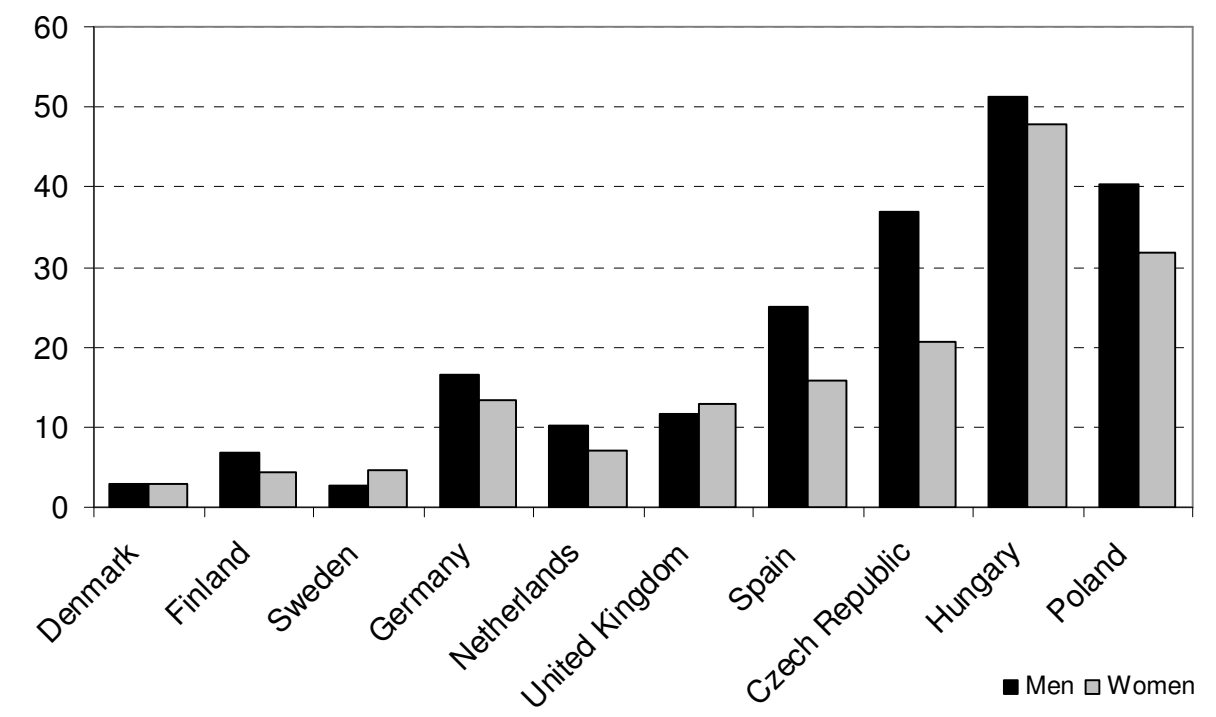

Figure 1: Men should have more right to job than women when jobs are scarce? Proportion agreeing with the statement (weight by design). 
We find that there is growing acceptance of women's equal rights for employment as seen in Figure 1. This response also mirrors the growing numbers of mothers in the labour market. That over two thirds of men in most of our countries do not agree that men's employment should be prioritized suggests that support for the single male breadwinner earner is on the wane (DiPrete et. al 2003). Weakest support is found in Sweden, Denmark and Finland, with less than 7 percent of men and women believing that men should have precedence over women when there is a shortage of jobs. Our CEE countries stand out as having the most traditional gender equality attitudes, even when considering employment. A surprisingly higher proportion of Hungarian women than men believe this.

Contrastingly, gender equality in the family does not have the same support and the assumption remains that women are mainly responsible for care in the family. We find significant proportions of men and women still agree that women should be willing to cut down on their employment for the sake of the family. Over 40 percent in all these countries except, the Netherlands and Scandinavian societies (see Figure 2).

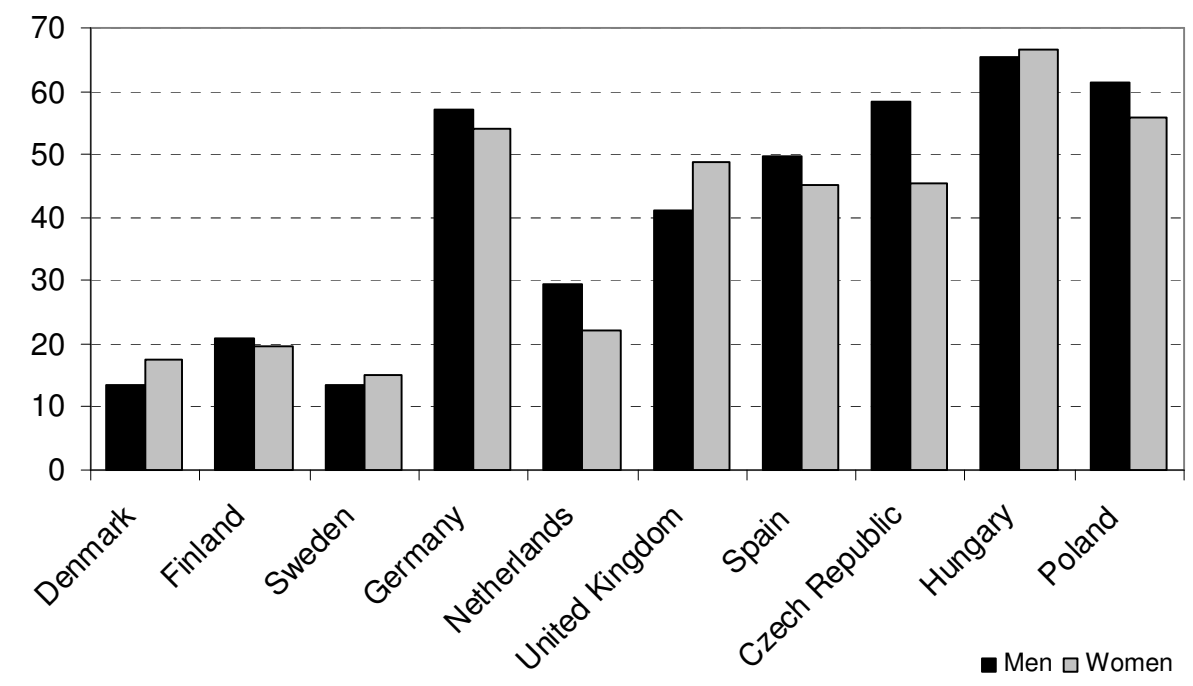

Figure 2: A woman should be prepared to cut down on her paid work for the sake of the family? Proportion agreeing with the statement (weight by design).

Considering WFB as value to be achieved, we find strong consensus for the importance family over careers. The analyses of Work Family Balance norms around family and job priorities reveal the extent to which WFB has become a hegemonic norm in EU countries (see Figure 3). Similarly, the belief that men and women should have equal responsibility for home and family has gained widespread acceptance; around 80-90 percent of both men and women take this position, though women on average are slightly more positive (see Figure 4). We see the same high proportions of men and women who agree that family should be your main priority in life. 


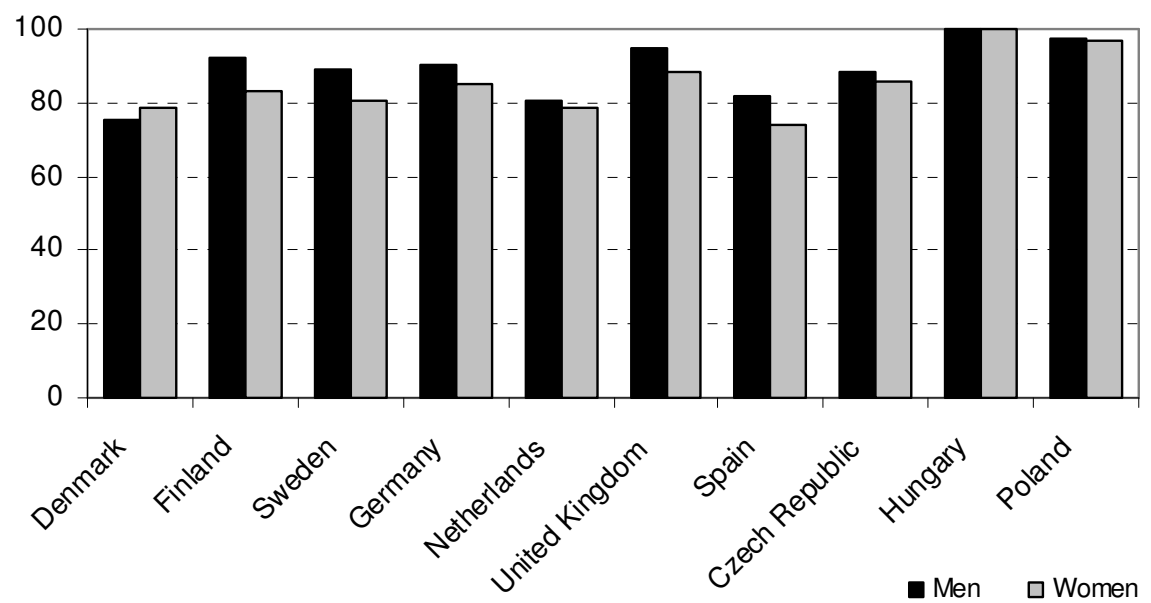

Figure 3: A person's family should be main priority in life? Proportion agreeing with the statement (weight by design).

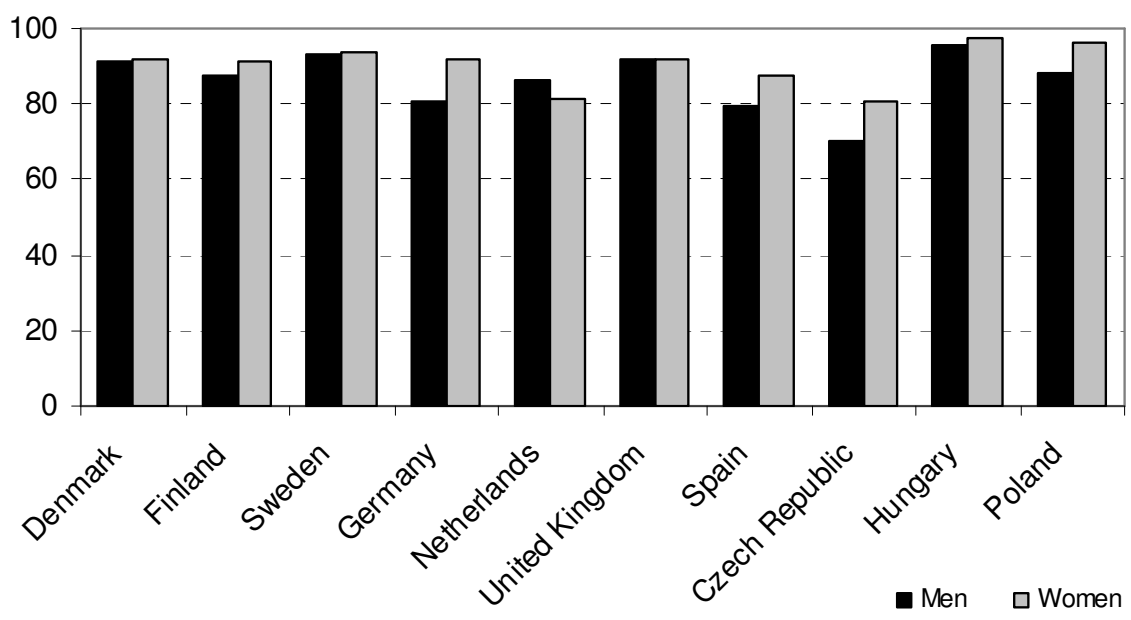

Figure 4: Men should take as much responsibility as women for home and children? Proportion agreeing with the statement (weight by design).

Most relevant to WFB, the vast majority of men and women agreed that combining work and responsibility is a priority when it comes to choosing a job (see Figure 5). Not just women, but the overwhelming majority of men said that they place importance on being able to find jobs that allow them to combine employment with family responsibilities. The gap between these norms and actual practices, however, is revealed in their actual working times. 


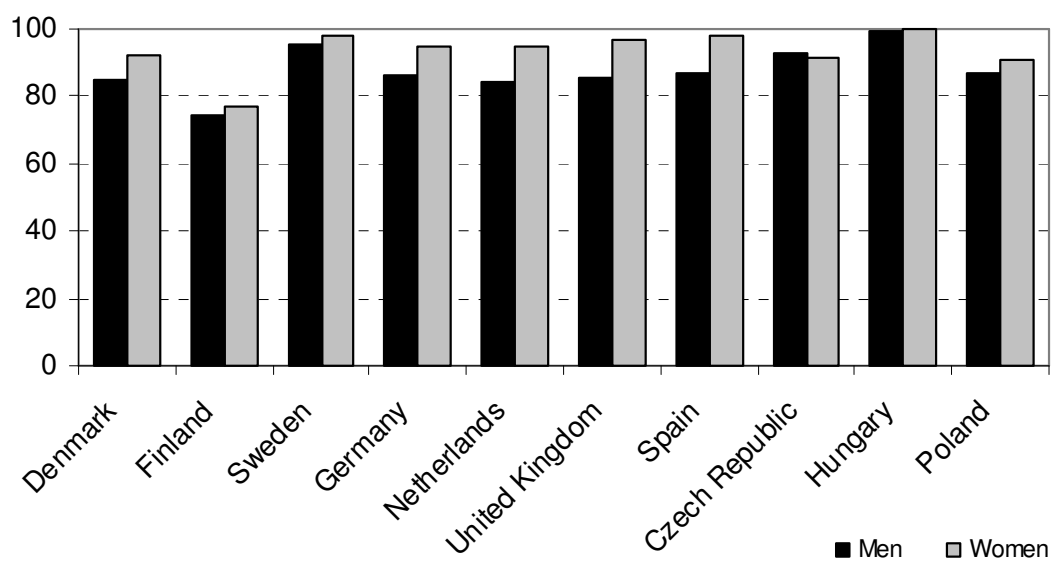

Figure 5: Proportion stating that it is important, when choosing a job, that the work allows them to combine work and family life (weighted by design).

The gap between norms and practices is apparent, especially in father's working times. Forty percent or more of fathers are working more than 40 hours a week (See Figure 6). Over sixty percent of the fathers in the CEE countries, Germany and the UK are working more than 40 hours per week, and over 40 percent of the fathers in the CEE countries are working more than 48 hours per week (figure not shown). A significant proportion of fathers in the Scandinavian countries, with the most family friendly policies for fathers, are also working long hours. Women tend to work less than 40 hours a week; the exceptions are women in the Czech Republic and Poland in which over 40 percent of women are working over 40 hours.

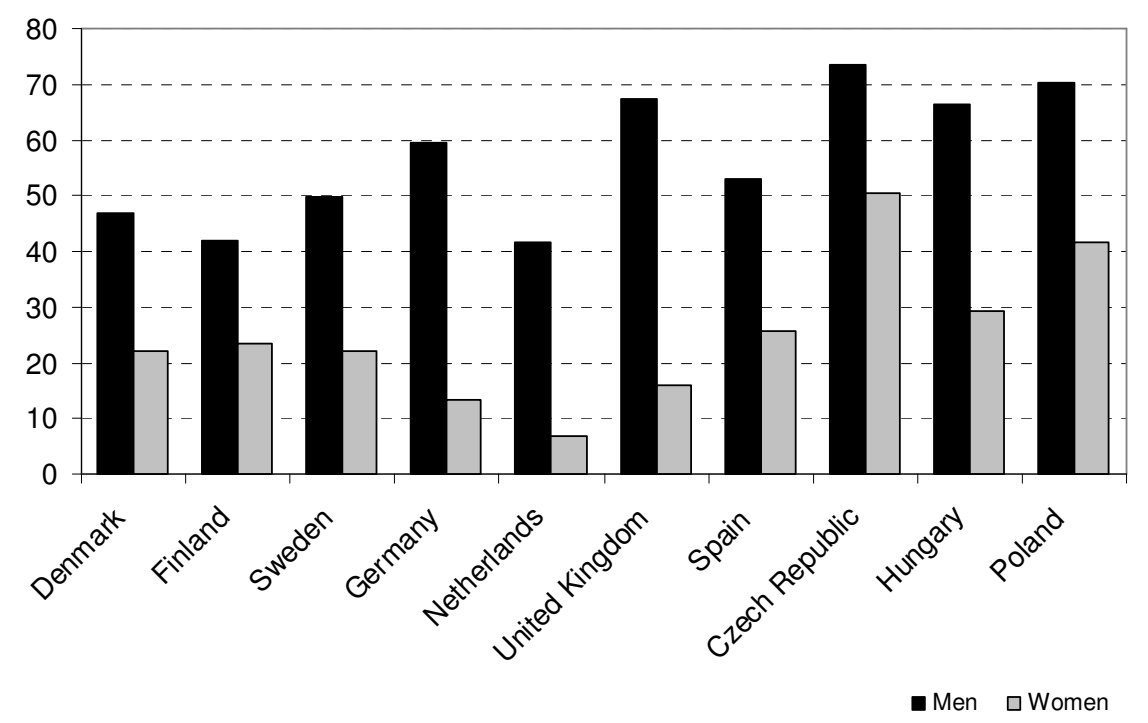

Figure 6: Proportion men and women working more than 40 hours/week (weighted by design). 


\section{Time and Flexibility}

In the next section we concentrate specifically on capabilities and working time.

Time: A framework for WFB necessitates a focus on time as a resource that involves competing claims in the family and workplace. Time budget studies provide us with a lens on the household and time-use in families, but they do not offer us an analytical framework for interpreting the broader processes that shape the organization of time beyond the individual household level. Time is not only a matter of hours, but also a matter of time spent in different activities and how they are valued and devalued in terms of compensation and career trajectories. Time from this perspective can be viewed as a redistributive resource in welfare state research, though this aspect of well-being is not acknowledged in the vast majority of comparative studies of welfare regimes. Time has a structural component that reflects working time regimes. Specific policies regulating what is a full-time work week reproduce these norms, but may also be ignored in workplace organizations and specific workplace cultures.

Flexibility: Flexibility in work is dependent upon whether it is employer or employee driven. As discussed above, it can be a policy that promotes a better WFB or it can weaken capabilities to spend more time with one's family. On the one hand, we might assume that those with the greatest flexibility and control over the work situation and pace of work are best able to respond and cope with the needs of family situations. On the other hand, those with the most autonomy often have jobs that place the most demands on them. There is also gender aspect in flexibility and autonomy: women who have short hours tend to be the least attached to the labour market and often work in the home (telemarketing, for example); these jobs often have flexibility and autonomy in terms of when they begin work and the pace of work, but not autonomy over the tasks of their work. Men in flexible jobs tend to be high earners with more autonomy over their work tasks.

We use two variables for working hours (1) actual working hours and (2) normative working hours. The normative hours is considered to be the work time regime in a specific country. It is the amount of hours (mode value) most men and women are working. The main variable in the analysis is capability hours, how many hours an individual would choose to work, given that the wage proportionally would increase or decrease.

Our analyses of flexibility/autonomy in work design is based upon a measure that includes how much the management at the workplace allows the respondent to decide how his/hers own daily work is organised, and if the respondent can choose or change is/hers pace of work. (A fuller description of the Variable List appears in the Appendix.) 


\section{Work hours and Capabilities Hours}

The assumption in economic theory is that workers preferred hours correspond to actual hours (Becker 1991), but this notion that working hours has been optimally set is directly challenged in Sen's framework. Lee and McCain (2006) in their analysis of working time capabilities affirm that working time capabilities in market economies are constrained. Our data allows us to see the relationship between what individuals say that would like to do with the actual hours in different institutional contexts: highlighting different dimensions in working time capabilities.

Considering working time capability, we focus on one question in the ESS module that allows us to compare actual working hours with how many hours individual parents would choose to work, bearing in mind that earnings would go up or down according to how many hours they work. Compared to questions in many surveys that ask how many hours you would like to work, in fact, this is a capabilities question because it distinguishes between what we desire and what is possible (our potential agency. the possibility to choose). As our point of departure is the capability approach, we do not consider the question on how many hours you would like to work if you would lose or gain pay as a matter of preferences. The question takes in many aspects of agency in WFB: most directly, economic constraints in the household as well as person's sense of risk and security in their general well being. Moreover, job security, and partner's economic and job situation would inhibit or allow the possibility of being able to choose to work less hours. Other factors influencing the possibilities to work more or fewer hours involve working time norms, work organizational cultures and care responsibilities. The responses reflect conditions and constraints. One could see them as conditional preferences, but this in essence reflects capabilities. Therefore we use the term capabilities hours, much in the same way that Lee and McCain (2006) speak of working time capability.

Given that for the most part a person's work hours reflect what they do in light of what they have achieved, it is not surprising that the gap between actual weekly hours and capabilities hours is not wider (see Figure 7-9).

Comparing men and women's capabilities hours (Figure 7), we show that in general women claim that they would work less hours than men. The gender gap in preferences is highest in the UK, Belgium and Germany.

To capture agency inequalities and capabilities, we compared the difference between actual hours and capabilities hours. Looking at men's capabilities hours, we see that the greatest agency inequalities exist in CEE countries (see Figure 8). For men, in all countries, but one (Poland, in which the average weekly hours were above 45 hours a week), the average capabilities hours were slightly less than actual working hours. We assume that when Polish and Czech men say that would like to work as much as high as 47 and 55.4 hours per week, if they it means an increase in pay, they are revealing more about the economic constraints in their lives than what they might actually desire. Not to be forgotten is that 86.6 percent of Polish fathers and 92.6 Czech fathers say that a priority in choosing employment is the ability to combine work and 
family life. Fathers in Sweden, Germany, Netherlands would reduce their hours substantially, below the 40 hour work week. Danish men get the prize as fathers work the least hours and would want to work the least hours, even if it means a loss of pay. Men in the UK are among the most time poor among the EU 15 countries; they would choose to reduce their hours by six hours, even if it meant a consequent hourly loss of income.

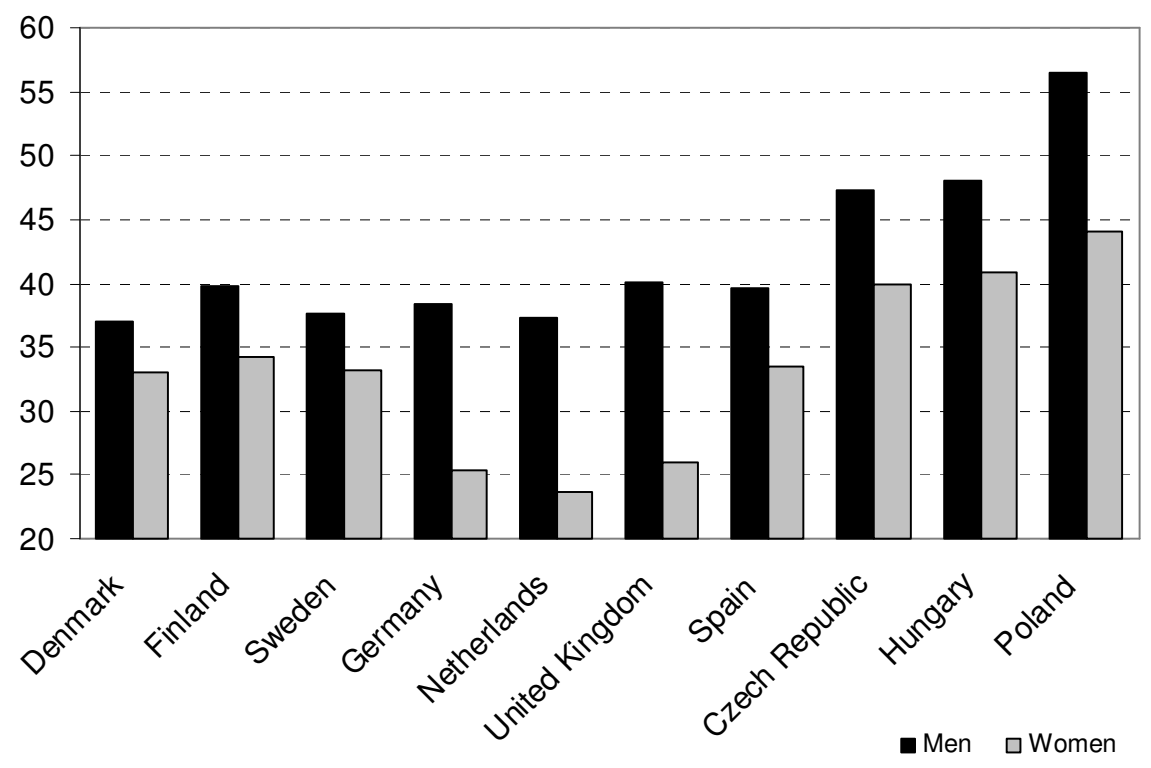

Figure 7: The average preferred working hours for men and women (weighted by design).

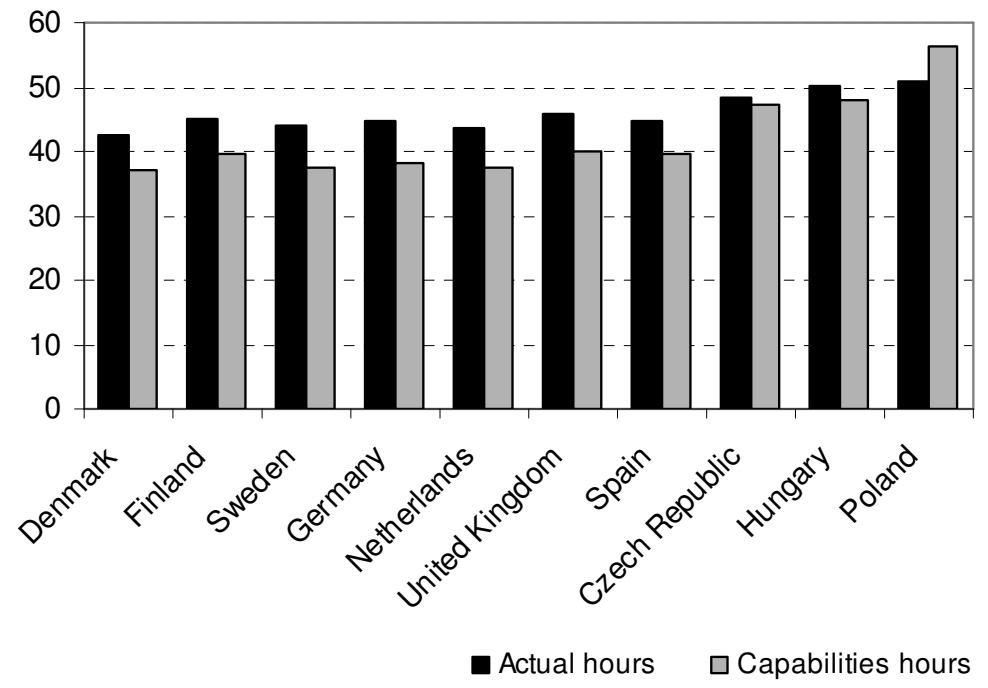

Figure 8: Fathers' working hours. Comparing actual work hour and preferred hours/week (weighted by design). 


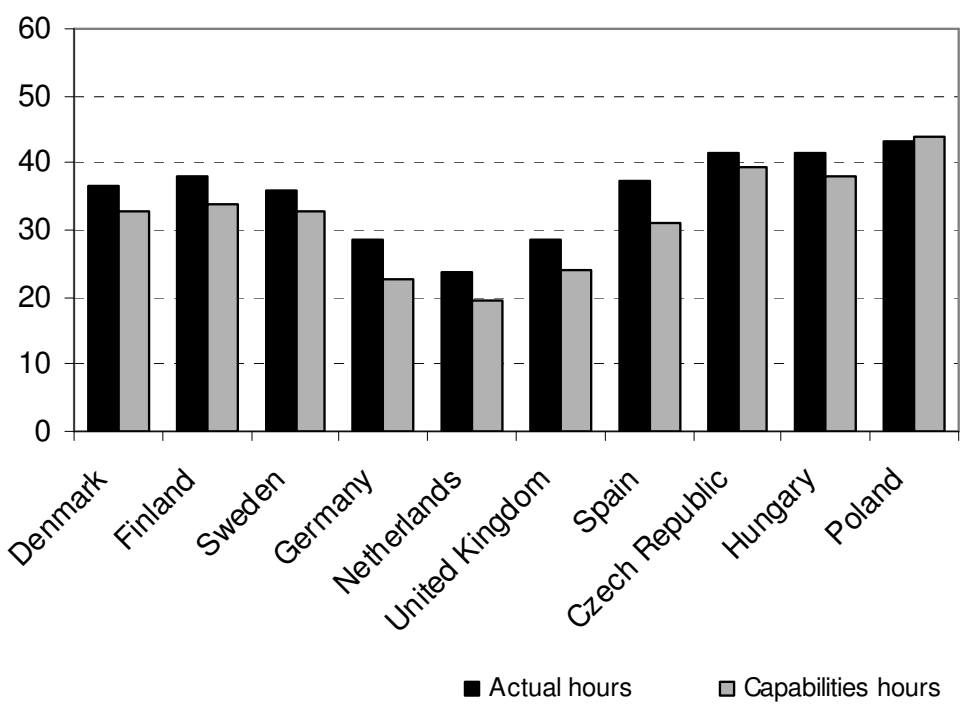

Figure 9: Mothers' working hours. Comparing actual work hour and preferred hours/week (weighted by design).

Considering women's capabilities hours, we are not surprised by the fact that they have much lower average actual hours and lower preferred hours than men (Figure 9) in light of their care responsibilities. Still, we find a similar pattern in the CEE countries for both men and women; high their preferred hours compared to actual hours are also high, 40 hour or more. The greatest gap between actual hours and capabilities hours can be found among women in Finland (five hours) from 39 to 34 hours At the low end of the scale are women in the Netherlands who want to work the fewest hours per week and have low average working times, a result that does not fit the standard view that those working short time hours always would prefer to work more hours. a Sen's capabilities approach takes into account the idea that not only actual hours but preferred hours can be adaptive: bounded by a range of social and institutional factors, including gendered norms around care, lack of daycare facilities, and inadequate institutional supports and infrastructure for WFB in schooling times, alongside individual factors in the household, including partner's working times and flexibility.

In order capture flexibility we have created a combined measure that includes two ESS questions. One concerns the extent to which the management at the workplace allows the respondent to decide how his/hers own daily work is organised, and two, if the respondent can choose or change his/hers pace of work. We also use normative hours (the mode, which in most cases is the contractual hours). We grouped our countries in welfare regime categories described above. ${ }^{23}$ 


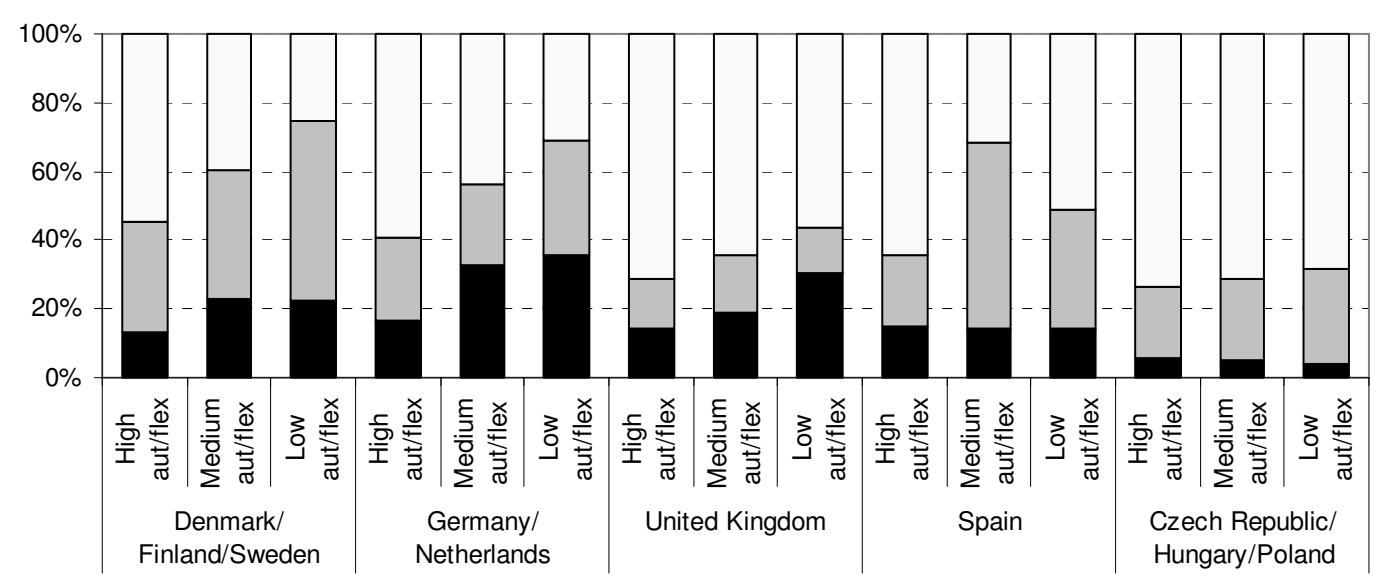

Works less than the norm $\square$ Normative working hour $\square$ Works more than the norm

Figure 10: Fathers' working hours in relation to work place autonomy/flexibility (weighted by population and design).

The relationship between fathers' working hours and workplace autonomy and flexibility show the same pattern in the Nordic cluster, Germany/the Netherlands and the UK (Figure 10 above). Those with a high degree of workplace autonomy/flexibility work more than the normative hours, and a smaller proportion of those with a low degree of autonomy work more than the normative hours. In the UK, a society with a long working time regime; those with high autonomy/flexibility tend to work the longest hours, but the differences are not that pronounced (as both those with high and low autonomy are working long hours). In Spain, this bifurcated pattern is even clearer. Those in the high and those in the low autonomy/flexibility categories work the most hours. For the latter, we can assume that long working hours reflect precarious and low-paying jobs; for the former, high autonomy/flexible jobs are more work intensive. In the CEE countries, men are working long hours irrespective of work place autonomy.

Given that mothers with young children usually do not work long hours within and across our clusters, we did not expect to see the same patterns that we found for fathers. However we did find some evidence (Figure 11) that those with high autonomy/flexibility tend to work longer hours, except in the CEE countries. In most of our countries women who work less than the normal hours tend to be in those in jobs with the least flexibility/autonomy, that is, their ability to organize their work and their pace or work.

These findings are suggestive for comparative analysis of WFB in which the capabilities approach is applied across different institutional contexts and welfare regime configurations. Since the presentation of these results at the annual RECWOWE meeting, we developed a model in which we incorporate regime effects with capability variables discussed above: autonomy/flexibility, perceptions of job and income security along with individual characteristics, including age, education, 
and partner's hours (Hobson and Fahlén 2009). We focus on fathers in this study because their working times follow more consistent patterns than mothers.

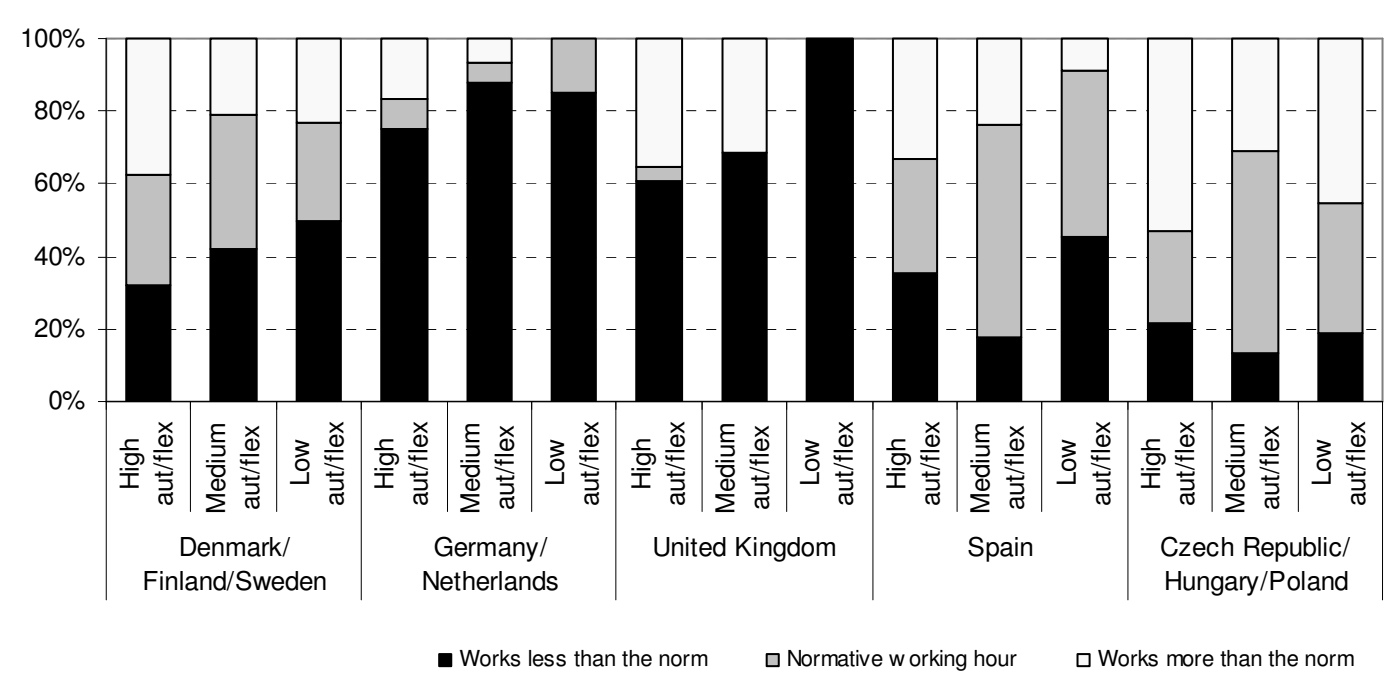

Figure 11: Mothers' working hours in relation to work place autonomy (weighted by population and design).

In this analysis we use a series of stepwise models in which capability hours in which our dependent variable is a binary variable (see Appendix for a fuller description of the variables). 
Table 1: Logistic regression. Capabilities hours - to choose to work less hours per week (weight by population and design).

\begin{tabular}{|c|c|c|c|}
\hline & Model 1 & Model 2 & Model 3 \\
\hline \multicolumn{4}{|l|}{ Working hours } \\
\hline Normative working hour (ref.) & 1 & 1 & 1 \\
\hline Works less than the norm & $0.41 * * *$ & $0.35 * * *$ & $0.30 * * *$ \\
\hline Works more than the norm & $4.10 * * *$ & $4.72 * * *$ & $7.77 * * *$ \\
\hline \multicolumn{4}{|l|}{ Age } \\
\hline 30-42 year (ref.) & & 1 & 1 \\
\hline 20-29 year & & 0.74 & 0.96 \\
\hline 43-55 year & & 1.12 & 0.95 \\
\hline \multicolumn{4}{|l|}{ Education } \\
\hline Upper secondary level (ref.) & & 1 & 1 \\
\hline Lower secondary or less & & 0.95 & 1.16 \\
\hline Tertiary level & & $2.12 * * *$ & $2.16 * * *$ \\
\hline \multicolumn{4}{|l|}{ Partners work hours } \\
\hline Works more than 37 h/week (ref.) & & 1 & 1 \\
\hline Not working & & $1.65 * * *$ & 0.93 \\
\hline Works less than $26 \mathrm{~h} /$ week & & $2.12 * * *$ & 1.01 \\
\hline Works $26-37 \mathrm{~h} /$ week & & $1.62 *$ & 0.95 \\
\hline \multicolumn{4}{|l|}{ Household economy } \\
\hline Manageably economy (ref.) & & 1 & 1 \\
\hline Solid economy & & $1.69 * * *$ & 1.32 \\
\hline Insecure economic situation & & 0.77 & 1.12 \\
\hline \multicolumn{4}{|l|}{ Employment situation } \\
\hline Limited/no employment contract (ref.) & & 1 & 1 \\
\hline Unlimited employment contract & & $1.79 * * *$ & 1.29 \\
\hline Self-employed & & 1.27 & 1.10 \\
\hline \multicolumn{4}{|l|}{ Work autonomy/flexibility } \\
\hline High autonomy/flexibility (ref.) & & 1 & 1 \\
\hline Low autonomy/flexibility & & 1.16 & $1.77 * * *$ \\
\hline Medium autonomy/flexibility & & 1.08 & 1.29 \\
\hline \multicolumn{4}{|l|}{ Welfare regimes } \\
\hline Nordic countries (ref.) & & & 1 \\
\hline Germany/The Netherlands & & & $2.19 * * *$ \\
\hline United Kingdom & & & 0.83 \\
\hline Spain & & & 1.18 \\
\hline CEE countries & & & $0.11 * * *$ \\
\hline Nagelkerke R Square & 0.21 & 0.30 & 0.44 \\
\hline -2 Log likelihood & $2005.600 * * *$ & $1867.942 * * *$ & $1627.154 * * *$ \\
\hline
\end{tabular}

$* * * p<0.001 . * * p<0.01 . * p<0.05$ 
Model 1 considering capabilities hours on actual work hours, we find what one would expect: fathers who work less than the normative country specific work hours (the working time regime) are less willing to consider working less hours compared to fathers who are working the normative/contractual hours. Those fathers who work more than the normative weekly hours are more likely to reduce their hours compared to those working the normative hours. Looking at individual characteristics, which appeared in our capabilities set as individual resources/situated agency, we see that the highly educated are more likely to want to reduce their hours compared to those with high school education (all else equal). This association becomes stronger even after we introduce regime clusters in the model. Partner's hours are important, but lose their significance after considering the institutional context, embedded in our regime type. The perception of one's household economy on capabilities hours has a significant effect in Model 2. Those with an insecure economic situation would be more willing to work less even if it meant a reduction in pay compared to those with a manageable economic situation (all else equal). However this loses significance when regime clusters are taken into account (Model 3 ), indicating that there is real divergence across our countries in perception of economic well being. There is a fairly strong relation between employment situation (limited/fixed contracts) and capability hours seen in Model 2 that increases somewhat after controlling for regime cluster (Model 3). Fathers with an insecure employment are more likely to want to reduce their work hours compared to fathers with a secure employment. Work place autonomy/flexibility and capabilities hours, become important after we introduce the regime clusters, suggesting that work place autonomy/flexibility varies across the regime clusters, and when controlling for this. Not surprisingly, we find that compared to fathers with a high work place autonomy/flexibility, fathers with low level of autonomy/flexibility are more likely wanting to work less.

In Model 3, we have used the Nordic countries as a referent category because fathers have the most opportunities to organize work and care time patterns: the right to reduce hours has been a right for all parents with kids under school age for many years; in some workplaces this right extends up to age twelve. In these countries, there are strong policy and discursive supports for WFB (conversion factors in Sen's terminology), particularly for fathers who are the focus in this analysis. Fathers feel legitimated to make claims for family, based on laws as well as norms. There is both security in employment and a sense of well being and satisfaction.

When we compare our Nordic regime countries with our two Conservative regimes countries, fathers in Germany/the Netherlands are more likely to want to decrease their work hours and take less pay. We suggest that this result reflects a certain level of security in employment in both these coordinated market economies (see Hall and Sockice 2001), as well as weak father friendly policies and gendered norms around care in families (see Knijn and Kremer 1997; Pfau-Effinger 2005). 
OECD-statistics show that Germany and the Netherlands score higher on the overall Employment Legislation Protection-index compared to the Nordic countries (except for Sweden): (see ELP-index scores: OECD Employment Outlook 2004, 1999). Furthermore, the family policies in the Conservative cluster do not support active fathering compared to the Nordic countries (OECD, Babies and Bosses). ${ }^{24}$

At the other end of the working time regime and WFB, are the fathers in the CEE countries. When compared with the Nordic countries, they are much less likely to consider reducing their work hours (all else equal). This suggests that fathers in our CEE countries have the least capabilities to achieve a WFB, that reflect multiple factors; low employment protection (OECD 2004), lack of father friendly policies (OECD Babies and Bosses), stronger male-breadwinner norms, and more widespread economic precariousness

\section{Institutional context and capabilities}

The results show that some clusters when compared with our referent Nordic category have a positive association with capabilities hours while others show the reverse effect: they would not reduce hours if it meant lower pay. This can be understood in terms of different mechanisms operating that limit a persons agency (potential to be or do something), which involve promotion of a person's well being and the pursuit of agency ${ }^{25}$ The institutional context play a crucial role in creating opportunities to make choices for WFB and quality of life.

(1) These findings suggest that a lack of well being freedom binders fathers' agency potential to create a WFB in CEE countries. Sen (2006) maintains that he does not want to reduce all agency inequalities to well being, nevertheless, those lacking basic functionings would have the greatest barriers for exercising agency to improve their quality of life, to choose the kind of life they value (agency freedom). The long working hours in CEE countries reflect the weak capabilities of both fathers and mothers who experience economic insecurity and risk in their daily lives and the failure of institutions to support quality of life. For most working fathers in these countries, is not within the realm of possibility to contemplate reducing hours if it means a reduction in pay. This is also true for many mothers working in the CEE countries. These are societies in which individuals and families experienced a dramatic change from stable and predictable futures to uncertainties in employment after the transformation to a market economy (Hobson and Oláh 2006).

(2) Our findings suggest that well being freedom does not necessarily result in agency achievement as seen in Conservative regime countries (Germany and The Netherlands) in which there is a fairly high standard of living (well being freedom) and the existence of policies and rights for WFB. Fathers in Germany and Netherlands would reduce hours even if means loss of pay, but standing in the way are barriers for WFB, including gendered norms in society, gendered expectations around men's and women's care responsibilities and organizational work cultures. The positive association reflects an agency gap between what is desired - better WFB and quality 
of life and one's capabilities to achieve it. In essence, these fathers cannot convert resources into capabilities.

Our analysis in the model has underscored the importance of institutional context. First, situated agency exists within a specific institutional context and welfare regime configuration, as other studies of gender and work have confirmed. This analysis also suggests that one's ability even to contemplate a change in quality of life is embedded in institutional setting.

\section{Conclusion: Implications for Future Research}

Looking at the policy implications of WFB and flexibility, we see some indications that jobs with flexibility and autonomy do not always lead toward more possibilities for WFB, a finding that is implicit in the Perrons' (2006) study of gender and the New Economy. More research is needed to consider the complex relationships between flexibility, working time regimes and work intensity, in light of our framework on capabilities and agency for WFB.

In order to apply our model of the capability set, we need to build in institutional level macro-indicators that would allow for more multi-layered types of analysis on time as a redistribution resource, including types of jobs and job protections. We need to build in other institutional level indicators, including union density, level of employment, and flexibility/flexicurity. These and other macro level variables will be incorporated into the next phase of our analysis, using the data sources that have been collected by the European Data Archive, EDACWOWE.

Our preliminary analysis also indicates the need for more qualitative data and interpretative theoretical models that tap into the subjective states of agency. The model (below) illustrates our assumptions about institutional context and agency and capabilities. In the context of WFB, we operationalize agency in terms of a sense of entitlement to make a claim in the family and in the workplace. These encompass the capabilities to challenge norms around working times and workplace cultures. Subjective states of efficacy to make claims are linked to institutional and societal settings, which appear in the model as conversion factors (not just rights, but the ability to exercise them). As Model 2 suggests, we assume that institutional contexts not only shape access to resources, but also subjective states of efficacy. Agency is therefore embedded in institutional contexts with specific policies and their implementation; rights/social rights, as well as discursive terrains that enhance the sense of entitlement to challenge gendered norms. 


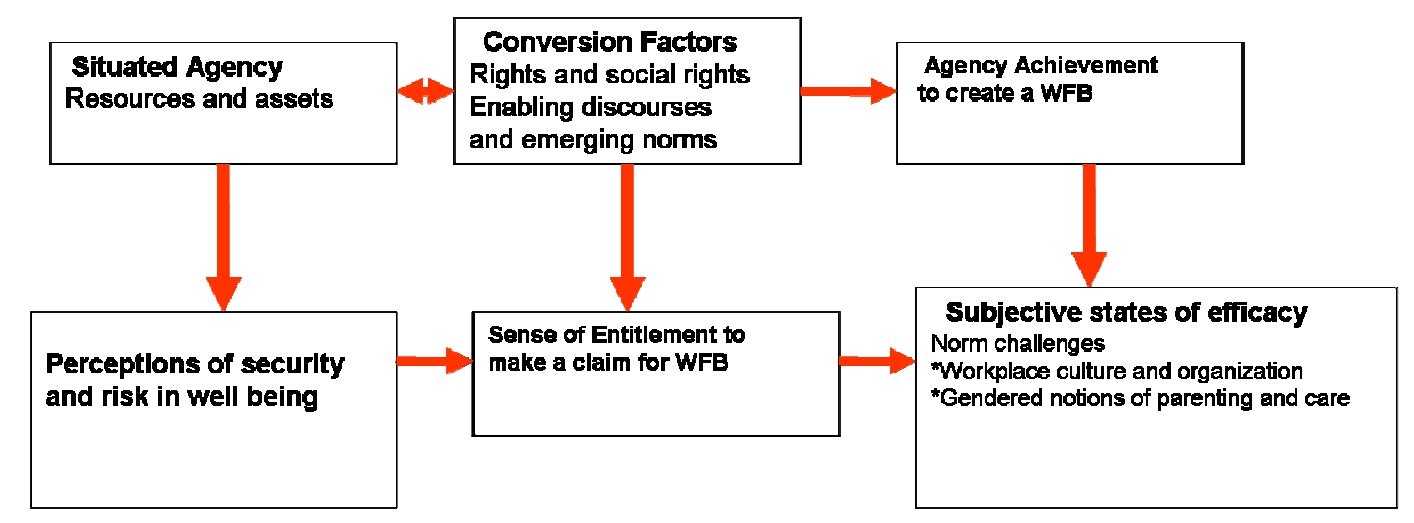

Model 2: How the Institutional/policy level and subjective states work in tandem

From our analysis of the ESS data, we could only infer on the capabilities and agency of individuals to create a WFB, considering individual and institutional resources. The attitudinal data on gender and family and work and family priorities only permitted a narrow lens on norms and norm construction. We could analyze conversion factors, but not conversion processes: In order to tap into subjective states of agency requires a different survey design tailored to the capabilities approach.

In order to tap into subjective states of agency, we have designed a WFB survey tailored to the capabilities approach, which builds upon the indicators and assumptions in the capability set (Model 1) and the dimensions of subjective states of efficacy and empowerment inferred in Model 2. This survey includes innovative strategies. First, we are not just asking what individuals do, but their sense of entitlement to make a claim across multiples sites: the household, the work organization and specific workplace. We also seek to capture the multilayered aspects of workplace organization and workplace cultures that constrain and enable parents from making a claim for care (leaves, and requests for reduced or flexible hours). The most obvious constraints are formal and formal rules, norms and expectations of working time and work commitment. These can operate at different levels; managerial, work team and collegial. (Bygren and Duvander 2004).

There are subtle ways of enforcing norms around working times and work commitment. Narratives of risk travel through workplaces about persons who have lost a position or experienced discrimination because they are perceived as prioritizing family over job commitment. Norms also travel through networks outside of the workplace among family, friends and in communities, which can lead to a reinforcement of, or challenge to, gendered norms (we have included a network component into the survey). 
The survey, implemented in two cities, Budapest and Stockholm, and to be conducted in a Japanese city in the near future, operationalises the capabilities framework in empirical research. It allows us to capture the dimension of subjectively experienced tensions in capabilities, and the agency gap in WFB both within and across societies. This dimension is crucial for developing research agendas currently prioritized at the European level: the relationship between quality of work and quality of life.

The survey questionnaire we are implementing is based upon the indicators and assumptions in the capability set (Model 1) and the dimensions of subjective states of efficacy and empowerment inferred in Model 2. This survey includes innovative strategies: First, we are not just asking what individuals do, but their sense of entitlement to make a claim across multiples sites: the household, the work organization and specific workplace. We also seek to capture the multilayered aspects of workplace organization and workplace cultures that constrain and enable parents from making a claim for care (leaves, and requests for reduced or flexible hours). The most obvious constraints are formal and formal rules, norms and expectations of working time and work commitment. These can operate at different levels; managerial, work team and collegial. There are subtle ways of enforcing norms and we introduce questions of what are the expectations for men and women in workplaces in terms of working times, care leaves (Bygren and Duvander 2004). We use a formulation on the narratives of risk that travel through workplaces; here we ask whether individuals have heard about a person at their workplace who has lost a position or experienced discrimination because they are perceived as prioritizing family over job commitment. Another innovative component in the survey is a focus on networks and capabilities in providing support for WFB as well as reinforcing or challenged gendered norms in care. Finally through our open-ended questions we seek to offer individuals a way of expressing scenarios for WFB and what can be imagined. This survey incorporates an important dimension in RECWOWE, that of subjectively experienced tensions. It also provides strategies for research agendas currently prioritized at the European level, the relationship between quality of work and quality of life.

\footnotetext{
${ }^{1}$ Paper first presented at the RECWOWE state of the Art Conference, Warsaw, June 13

2 The multi-level agency and capabilities approach is also the starting point of our specific task to operationalize agency freedom and the capability to create a work family balance through the implementation of a unique pilot survey questionnaire with a capabilities design.

${ }^{3}$ Looking at EU countries up to 1999, Gauthier and Bortnik (2001) show that the UK is the exception with a replacement rate for a woman industrial worker is below 50 percent. Gornick and Meyers (2003) use a leave index (in the year 2000) in which they multiply number of weeks by replacement
} 
pay. Among their European countries, only the UK has a maternity leave index below twelve. Hobson and Oláh (2006) have similar findings, and they include Post-Social Transition Countries.

4 The Directive provides statutory protection for equal treatment of part-time workers on a pro-rata basis with comparable full time workers.

${ }^{5}$ Ronnie Eklund (2001) referring to the Directive as the Chewing Gum Directive, highlights its vague and elastic parameters. He makes the point that the Directive follows a tendency in EU to leave the regulation of social policy to the social partners - assuming that they will take over the initiative in collective bargaining agreements.

${ }^{6}$ This is discussed in Part 3 of this paper.

${ }^{7}$ We discuss these below when considering WFB in light of Sen's theory of capabilities..

8 This is also the position in the OECD study, Babies and bosses, which concludes that family friendly policies can increase living standards, expand workforce, and have a positive effect on fertility (OECD 2007).

9 Studies of gender and welfare regimes brought this dimension in empirical and theoretical research agenda: For a review of this literature: see Hobson 2005.

10 Gupta and Ash (2008) in their analysis of heterosexual couples in the US also challenge the conventional bargaining models using a nonparametic approach to housework hours. They find that than not women's share of household earnings (relative earnings), but rather her absolute earnings has the most explanatory value when considering the division of time spent in housework.

11 Takahashi (2003) has shown that even in the Scandinavian countries with their highly developed WFB policies, latent power and societal norms operate to impede gender equality; see also Ahrne and Roman (1997).

${ }^{12}$ Comparing 38 European countries one recent study shows that in only four countries did they find more than 10 percent of the men had taken any leave: Luxembourg, Netherlands, Iceland, Norway and Sweden, three of which are Nordic countries. See EGGSIE, 2005, p.61

${ }^{13}$ For example in our current survey, we find that many fathers who are not taking formal parental leave work around the system, for example leave work early or work from home. One Norwegian research team found the fathers of young children reduce their actual hours, though not their contractual yours (see Dommermuth et al. 2007)

14 There is a contested literature debating this maintaining that maternity leaves can result in statistical discrimination: See Bergmann 1986.

${ }^{15}$ Hobson is not suggesting that maternity leave is a negative policy for women's employment, but rather it does not apply equally to men's care leaves: only women's care leaves in EU law are given full and unmitigated protections, as seen in the arguments in the EU court for pregnancy protections, which reflect prevailing norms are that are rooted in essentialist notions of motherhood (see McGlynn 2000).

${ }^{16}$ This concept will be discussed further in the following pages.

${ }^{17}$ Environmental factors as Sen applied them are most relevant to Developing countries

${ }^{18}$ Empirical data on the job share initiative in Netherlands illustrates that few couples took advantage of this scenario for a Work family balance (see Kremer 2001) A study by Knijn and van Wel (2001) compared families in 1998 and 2000 shows that only 9 percent of parents with children have taken 
advantage of this possibility of equal sharing: both work a maximum of 32 hours a week. The number of single earner families had declined from 29 percent to 9 percent; but this did not result in more equality in the family. Rather more women are working part time; 61 percent of families follow the 1 $1 / 2$ model family, that is a breadwinner father working more than 32 hours and mother working less than the standard work week (of 32 hours).

19 The aim of the European Social Survey is to collect information about changing attitudes, beliefs and behavior patterns; in 2004 an additional module on employment and family was added (European Social Survey 2005; www.europeansocialsurvey.org; 2005-11-28). The sample is representative for all persons above 15 years of age within private households in each country. The response rate varies from 46.9 percent to 79.3 depending on country with an effective sample of about 1,500 individuals.

${ }^{20}$ In choosing these countries for regime types, we follow conventions in regime clusters combining Korpi's typology of Dual Earner, Market Oriented and General Family Support (2002) and EspingAndersen's typology in the Three Worlds of Welfare Capitalism (1990).

${ }^{21}$ We would have liked to include Italy, but the data was not considered to be reliable.

22 In Figure 1-4 the response alternatives Agree strongly and Agree are collapsed into one category. Figure 5 presents the rates for the response alternative Very important/Important.

${ }^{23}$ By grouping our countries in these regime configuration clusters, we were able overcome the small sample sizes in some of the ESS countries.

${ }^{24}$ There has been recent change in German law and today there is a daddy quota in the parental leave scheme.

25 Sen's breaks these down into four categories of advantage: well being achievement; agency achievement; well being freedom; agency freedom, many of which overlap in the individual capability set (Sen 2006, p. 45) 


\section{Appendix}

\section{Variable List}

Working hour: We use two variables for working hours (1) actual working hours and (2) normative working hours. We use actual hours in our descriptive analysis. In our binary analysis we use a categorical variable on working hour. The three categories are if parents in actual time (over time included) works more than normative hours, works normative hours, and works less than normative hours. To capture both gender and within country differences in working hours, the categorical variable is based on the normative work hours for men and women (aged 20-55 years) per week within each country. The normative hours is considered to be the work time regime in a specific country. It is the amount of hours (mode value) most people are working. The work time regime is 40 hours per week in most of our selected countries, except for Denmark with a work time regime of 37 hours for both men and women. The work time regime for women in the

Capability hour: The variable called capability hour difference constitutes the differences between how many hours an individual would choose to work, given that the wage proportionally would increase or decrease and how many hours the individual actually works during a week, overtime included. In our regression analysis we use capability hours as the dependent variable, dichotomized into $0=$ wanting to work about the same ( \pm 1 hour) or more hours, and $1=$ wanting to work fewer hours.

Work place autonomy/flexibility: To be able to capture more than one dimension of the concept work place autonomy and flexibility we constructed a combined measure containing two items. The measure includes how much the management at the workplace allows the respondent to decide how his/hers own daily work is organised, and if the respondent can choose or change is/hers pace of work. These responses to these questions range from 1 to 10 , in which 1 equals no influence, and 10 equals total control. The consistency of these items were tested with Cronbach's Alpha, to explore to what degree the items are correlated to each other, and hence measure the same concept (Bohrnstedt and Knoke 1988; Björkman 2000). The value for men is 0.84 and 0.82 for women. A value exceeding 0.7 is considered as a very good scale consistency (Sharma 1996). We therefore consider our work place autonomy/flexibility measure to be consistent. In our analysis the variable has been divided into three equally distributed categories; low degree of work place autonomy/flexibility, medium autonomy/flexibility, and high degree of autonomy/flexibility. 


\section{References}

Agarwal, B. (1997). "Bargaining and Gender Relations: Within and Beyond the Household." Feminist Economics 3:1-51.

Agarwal, B., J. Humphries and I. Robeyns (2003). "Exploring the Challenges of Amartya Sen's Work and Ideas: An Introduction." Feminist Economics 9:3-12.

Ahrne, G. and C. Roman (1997). "Hemmet, barnen och makten: förhandlingar om arbete och pengar i familjen". SOU:1997:139: Stockholm: Fritzes.

Becker, Gary S. (1991). A treatise on the family. Cambridge, Mass.: Harvard Univ. Press.

Blossfield, H.P. and S. Drobenic. (2001). Careers of Couples in Contemporary Society. Oxford: Oxford University Press.

Blumstein, P., and P. Schwartz (1991). "Money and Ideology: Their impact on Power and the Division of Household Labour." In R.L. Blumberg (Ed.), Gender, Family, and Economy. Pp. 261-288. Sage.

Brennan, D. (2007). "Babies, Budgets, and Birthrates: Work/Family Policy in Australia 1996-2006." International Studies in Gender, State, and Society 14:31-57.

Browne, J., S. Deakin and F. Wilkinson (2004). "Capabilities, social rights and European market integration." In R. Salais, and R. Villeneuve (Eds.), Europe and the Politics of Capabilities. Pp. 205-221. Cambridge: Cambridge University Press.

Browne, J., S. Deakin and F. Wilkinson (2002). "Capabilities, Social Rights and European Market Integration." ESRC Centre for Business Research, University of Cambridge.

Bruning G, and J. Plantenga (1999). "Parental leave and equal opportunities: experiences in eight European countries." Journal of European Social Policy 9:195-209.

Bygren, M and A-Z. Duvander. (2006). "Parents' workplace situations and fathers' parental leave." Journal of Marriage and the Family 10.

Bygren, M. and A-Z. Duvander (2004). "Ingen annan på jobbet har ju varit pappaledig . . .' Papporna, deras arbetsplatser och deras pappaledighetsuttag." In M. Bygren, M. Gähler and M. Nermo (Eds.), Familj och Arbete: vardagsliv i förändring. Pp. 166-199. Stockholm: SNS Förlag.

Bunting, M. (2004). Willing Slaves: How the Overwork Culture is Ruling our Lives. London: Harper Collins.

Barnard, C., S. Deakin and R. Hobbs (2001). "Capabilities and rights: An emerging agenda for social policy?" Industrial Relations Journal 32:464-79.

Bittman, M., P. England, N. Folbre, L. Sayer and G. Matheson (2003). When does Gender Trump Money? Bargaining and Time in Household Work." AJS: 109: 1: 186214.

Björkman, N-M. (2000). Fyra metodologiska teman. Stockholm.

Blood, R.O and D.M Wolfe (1960): Husbands and Wives: The Dynamics of Marital Living. NY: Free Press. 
Bohrnstedt, G.W. and D. Knoke (1988). Statistics for Social Data Analysis. Itasca: F.E. Peacock Publishers, Inc.

Bradshaw. J, S.Kennedy, M.Kilkey. S.Hutton, A. Corden, T. Eardley, H. Holmes, and J.Neale (1996). Policy and Employment of Lone Parents in 20 Countries. The EU Report. York: European Observatory on National Family Policies. EU/University of York.

Brines, J. (1994) "Economic Dependency, Gender and the Division of Labour," AJS 100:2: 632-88.

Carson, M. (2004). From Common Market to Social Europe? Paradigm Shift and Institutional Change in European Union Policy on Food, Asbestos and Chemicals, and Gender Equality. Stockholm: Almqvist \& Wicksell.

Crompton, R. and M. Brockmann (2006). "Class, Gender and work-life articulation". In Perrons et al. (Eds.), Pp 103-123. Gender divisions and working time in the new economy: changing patterns of work, care and public policy in Europe and North America.. Cheltenham. Edward Elgar.

Crompton, R., and F. Harris (1998). "Explaining Women's Employment Patterns: 'Orientations to Work' Revisited." British Journal of Sociology 49:118-36.

Crompton, R., and C. Lyonette (2006). "Work-life 'Balance' in Britain and Europe." Acta Sociologica : 49:4; 379-93

Deakin, S. (2003): "Social rights and the market: An evolutionary perspective," in D.Burchell, S. Deakin, J, Michie, and J.Rubery (Eds.).Pp. 74-88. Systems of Production: Markets, organizations and performance. London: Routledge .

Deven, F. and P. Moss (2002). "Leave Arrangements for Parents: overview and future outlook." Community, Work \& Family 5:237-255.

DiPrete, T.A., S.P. Morgan, H. Engelhardt, and H. Pacalova (2003). "Do crossnational differences in the costs of children generate cross-national differences in fertility rates?" Population Research and Policy Review 22:439-47-

Dommermuth, L., R.H. Kitterod and E. Nymoen (2007) 'Fathers employment in a father-friendly welfare state. Does fatherhood affect men's working hours.' Paper presented at the Workshop: Changes in family Structures, fertility trends and parenthood practices in the Nordic Countries: Empirical evidence and challenges to public policy, 11-12 Oct, Klaekken Norway.

Duncan, S. (2005). "Mothering, class and rationality." Sociological Review. 51-76.

Duvendak, J.W. and M. Stavenuiter (Ed.). (2004). Working fathers, Caring men. The Hauge: Verwey-Jonker Institute.

Eklund, R. (2001). "The Chewing-Gum Directive - part-time work in the European Community." Pp. 55-78 in Festskrift till Hans Stark. Stockholm: Liber Amicorum.

England, P. and B. Kilbourne (1990). "Markets, Marriages and other Mates: The Problem of Power,." in R. Friedland and A.F. Robertson (Eds.). Beyond the Marketplace: Rethinking Economy and Society, Pp. 163-188. New York: Aldine de Gruyter. 
Esping-Andersen, G. (1999). "Social Foundations of Postindustrial Economies." Pp. 218 p. Oxford: Oxford University Press.

Esping-Andersen, G. (1990). The three worlds of welfare capitalism. Cambridge, UK: Polity Press.

European Commission (2003) Scoreboard on Implementing the Social Policy Agenda, Brussels : COM, 57 final.

European Commission (2002). Increasing Labour Force Participation and Promoting Active Ageing. Brussels: COM, 9 Final.

European expert Group on Gender, Social Exclusion and Employment (EGGSIE). (2005). 'Reconciliation of work and private life: A comparative review of thirty European Countries'. Luxembourg: European Commission.

European Social Survey A (2005). Sampling for the European Social Survey- Round 2: Principles and requirements. www.europeansocialsurvey.org; 2005-11-28

European Social Survey B (2005). Weighting European Social Survey Data. www.europeansocialsurvey.org; 2005-11-28

Fagan, C. (2004). "Gender and Working-time in Industrialized countries: practices and preferences." In J. Messenger (Ed.), Finding the Balance: Working-time and Workers' Needs and Preferences in Industrialized countries. Pp. 108-46. London: Routledge/the Institute for Labour Studies of the International Labour Organisation.

Fagan, C., A. Hegewisch and J. Pillinger (2006). "Out of time: why Britain needs a new approach to working time flexibility." Trades Union Congress.

Ferrarini, T. (2003). Parental leave institutions in eighteen post-war welfare states. Stockholm: Institute for Social Research.

Folbre, N. (1994). Who pays for the kids?: gender and the structure of constraint. London; New York: Routledge.

Folbre, N. (1995). "Engendering Economics: New Perspectives on Women, Work and Demographic Change." in Annual World Bank Conference on Development Economics. Washington DC: World Bank.

Gauthier, A.H. (2004). "Choices, oppurtunities and constraints on partnership, childbearing, and parenting: the policy responses." in Background paper for the European Population Forum. Geneva.

Gauthier, A.H. and A. Bortnik (2001). "Comparative maternity, parental and childacre database."

Gavanas, A. and F. Williams. (2008). "The Intersection of Child Care Regimes and Migration Regimes: a Three-country Study." In H. Lutz (Ed.), Migration and Domestic Work: a European Perspective on a Global Theme. Pp. 13-28. London, Routledge.

Ginn, J , S. Arber, J. Brannen, A. Dale, S. Dex. P. Elias, P. Mass, J. Pall, C. Roberts, J. Rubery (1996). "Feminist fallacies: a reply to Hakim on women's employment." British Journal of Sociology 47:167-174. 
Gornick, J.C. and M.C. Meyers (2003). Families that work: Policies for reconciling parenthood and employment. New York: Russell Sage Foundation.

Gupta. S. and M. Ash. (2008). "Whoose mondy, whose time? A nonparametic approach to modelling time spent on housework in the United States." Feminist Economics, 14: 1: 193-120.

Haas, L. and P. Hwang (2000). "Programs and policies promoting women's economic equality and men's sharing of childcare in Sweden". In L. Haas, P. Hwang, and G. Russell (Eds.), Organizational Change and Gender Equity. Pp. 133-161. Thousand Oaks, CA: Sage.

Hakim, C. (2003). "A new approach to explaining fertility patterns: Preference theory." Population and Development Review 29:349.

Hakim, C. (2000). Work-lifestyle choices in the 21st Century : preference theory. Oxford: Oxford University Press,.

Hall, P. and D. Sockice, (Eds.). (2001). Varieties of Capitalism: The Institutional Foundations of Comparative Advantage. Oxford: Oxford University Press.

Hantrais, L.(2000). Gendered Policies in Europe: Reconciling Employment and Family Life. London: Macmillan.

Hobson, B. and S. Fahlén (2009). Two Scenarios for European Fathers: Adversity and Risk? Opportunities and Agency for a Work Family Balance. Annals The Annals of the American Academy of Political and Social Science. 64

Hobson, B., A-Z. Duvander and K. Halldén (2006) 'Men and Women's Agency and Capabilities to Create a Worklife Balance in Diverse and Changing Institutional Contexts'. In J. Lewis (Ed.) Children, Family Policies and Welfare State Change. Pp 267-97 Cheltenham: Edward Elgar.

Hobson, B. and L,Sz. Oláh. (2006). "Birthstrikes? Agency and Capabilities in the Reconciliation of Employment and Family." Marriage \& Family Review 39:197-227.

Hobson, B. (2006). "The Evolution of the Women-Friendly State: Opportunities and Constraints in the Swedish Welfare State." In S. Razavi, and S. Hassim (Eds.), Gender and Social Policy in a Global Context: Uncovering the Gendered Structure of 'the Social'. Pp. 151-172. Palgrave MacMillan

Hobson, B. and M. Lindholm. (1997). "Collective Identities, Power Resources, and the Making of Welfare States, "Theory and Society. 26: 475-508.

Hobson, B. (1994). "Solo Mothers, Policy Regimes and the Logics of Gender." In D. Sainsbury (Ed.), Gendering welfare state. Pp. 170-187- London: Sage.

Hobson, B. (1990). "No Exit No Voice: women's economic dependency and the welfare state." Acta Sociologia 33:235-50.

Huber, E. and J.D. Stephens (2003). "Determinants of welfare state approaches to old and new social risks." In Database on labour statistics, ILO Bureau of statistics. Geneva. 
Iversen, V. (2003). "Intra-household Inequality: A Challenge for the Capability Approach?" Feminist Economics 9:93-116.

Knijn, T. and M. Kremer (1997). "Gender and the caring dimension of welfare states: Toward inclusive citizenship". Social Politics, 4(3):328-361.

Knijn, T. and F. van Wel (2001). Een wankel evenwicht. Arbeid en rorg in gezinnen met jonge kindern. Amsterdam: SWP:

Korpi, W., and J. Palme (1998). "The paradox of redistribution and strategies of equality: Welfare state institutions, inequality, and poverty in the western countries." American Sociological Review 63:661-687.

Korpi, W. (1983). The democratic class struggle. London ; Boston: Routledge \& K. Paul.

Kremer, M. (2001). "A Dutch Miracle for Women?" Social Politics. 8:2: 182-86.

Lee, S. and D. McCain (2006). "Working time capability: Towards realizign individual choice." In Boulin, J-Y, M. Lallement, J.C. Messenger, and F. Michon (Eds.), Decent working time: New trends; new issues. Pp. 65-82. Geneva: International Labour Office.

Lewis, J. (2004). "The gender settlement and social provision: the work-welfare relationship at the level of the household." In R. Salais, and R. Villeneuve (Eds.).Europe and the Politics of Capabilities. Pp. 239-271 ,. Cambridge: Cambridge University Press.

Lewis, J. (1997). "Gender and Welfare Regimes: Further Thoughts." Social Politics 4:160-77.

Lundberg, S., and R. Pollack (1996)."Bargaining and Distribution in Marriage."Journal of Economic Perspectives. 10:4:139-158.

Man K.Y. (2007). "Work Orientation and Wives' Employment Careers. an evaluation of Hakim's preference theory." Work and Occupations. 34: 4: 45-66.

McCann, D. (1994). "Regulating working time needs and preferences". In J. Messenger (Ed.) Finding the Balance: Working-time and Workers' Needs and Preferences in Industrialized countries. London: Routledge.

McDonald, P. (2000). "Gender equity, social institutions and the future of fertility." Journal of Population Research 17:1-16.

McGlynn, C. (2000). "Ideologies of Motherhood in European Community Sex Equality Law." European Law Journal 6:29-44.

Nash, J. (1950). "Two-Person Cooperative Games." Econometrica 21:128-40.

Nussbaum, M. (2003). "Capabilities as Fundamental Entitlements: Sen and Social Justice." Feminist Economics 2/3: 33-59

Nussbaum, M and A.Sen. (Eds) (1993). The Quality of Life. Oxford: Claredon Press.

OECD. (1999; 2004.) Employment Outlook. www.oecd.org/els/employment/outlook/download http://www.oecd.org/document/62/0,3343, en $26493392731935102 \quad 1 \quad 1 \quad 1 \quad 1,00$ html. 
OECD. (2007) Family database. Babies and Bosses - Reconciling Work and Family Life (Vol. 5): A Synthesis of Findings for OECD Countries. www.oecd.org/els/social/family

O'Connor, J- S., A.S, Orloff, and S. Shaver. (1999). States, markets, families : gender, liberalism and social policy in Australia, Canada, Great Britain and the United States. Cambridge: Cambridge University Press.

Orloff, A. S. (1993). "Gender and the Social Rights of Citizenship - the ComparativeAnalysis of Gender Relations and Welfare States." American Sociological Review 58:303328.

Pahl, J. (1989). Money and marriage. Basingstoke: Macmillan Education.

Perrons, D. (Ed.) (2006). Gender divisions and working time in the new economy : changing patterns of work, care and public policy in Europe and North America. Cheltenham: E. Elgar

Parent-Thirion, A., M.E. Fernández, J. Hurley and G. Vermeylen (2007). Fourth European Working Conditions Survey, Luxembourg: Office for Official Publications of the European Communities.

Perrons, D, C. Fagan, L. McDowell, K. Ray and K. Ward (2006) (Eds.). Gender divisions and working time in the new economy: changing patterns of work, care and public policy in Europe and North America. Cheltenham: E. Elgar.

Pfau-Effinger, B. (2005). "Culture and Welfare State Policies: reflections on a complex interaction." Social Policy 34:1-18.

Plantenga, J., J. Schippers and J. Siegers (1999). "Towards an Equal Division of Paid and Unpaid Work: The Case of the Netherlands." Journal of European Social Policy 9:99110 .

Proctor, I and M. Padfield (1999). "Work orientations and women's work : a critique of Hakim's theory of the heterogeneity of women." Gender and Work Organization. 13:6:3: 152-162-

Robeyns, I. (2003). "Sen's capability approach and gender inequality: Selecting relevant capabilities." Feminist Economics 9:61-92.

Rubery, J. (1998). Women and European employment. London: Routledge.

Salais, R., and Villeneuve, R. (Eds.). (2004), Europe and the Politics of Capabilities: Cambridge University Press.

Sen, A. (2006). "Capability and well-being." In M. Nussbaum and A. Sen (Eds.), The quality of life, Pp. 9-30 Oxford: OUP (reprinted from 1993 publication).

Sen, A. (2003). "Continuing the Conversation: Amaryta Sen talks with Bina Agarwal, Jane Humphries and Ingrid Robeyns." Feminist Economics. 9:2-3: 319-332.

Sen. A. (1999). Development as Freedom: Oxford: Oxford University Press.

Sen. (1992). Inequality Re-examined. Oxford: Oxford University Press.

Sen, A. (1990). "Gender and Cooperative Conflicts." In I. Tinker (Ed.), Persistent Inequalities: Women and World Development. Pp. 123-149. New York: Oxford University Press. 
Sharma, S. (1996). Applied Multivariate Techniques. New York: John Wiley \& Sons Inc.

Stragegki, M. (2004). "The Cooptation of Gender Concepts in EU Policies: The Case of "Reconciliation of Work of Family." Social Politics: International Studies in Gender, State, and Society 11:30-56.

Takahashi, M. (2003). "Gender dimensions in family life: A comparitive study of structural contrainst and power in Sweden and Japan." In G. Ahrne (Ed.), Stockholm Studies in Sociology. Stockholm.

Van Der Lippe, T.and P. Peters (Eds.) (2007). Competing Claims in Work and Family Life. Cheltenham: Edward Alger.

Walker, R., R. Goodwin and E. Cornwall (2000). "Work Patterns in Europe and Related Social Security Issues." In D. Pieters (Ed.),Changing Work Patterns and Social Security. Pp. 5-43. London: EISS Yearbook.

Wallace, C. (2002). "Household Strategies: Their Conceptual Relevance and Analytical Scope in Social Research." Sociology 36: 275-292. 


\section{Recent titles in this series}

download at http://www.socialpolicy.ed.ac.uk/recwowepudiac/working papers/

\begin{tabular}{|c|c|c|}
\hline \multicolumn{3}{|c|}{ Working Papers 2009} \\
\hline $10 / 09$ & $\begin{array}{l}\text { Fabio Bertozzi, } \\
\text { Giuliano Bonoli }\end{array}$ & Measuring Flexicurity at the Macro Level \\
\hline 09/09 & $\begin{array}{l}\text { Silja Häusermann, } \\
\text { Hanna Schwander }\end{array}$ & Identifying outsiders across countries \\
\hline 08/09 & María C. González & $\begin{array}{l}\text { Workers' Involvement at the workplace and Job } \\
\text { Quality in Europe }\end{array}$ \\
\hline 07/09 & $\begin{array}{l}\text { Rodolfo Gutiérrez, } \\
\text { Ana Guillén, } \\
\text { Ramón Peña-Casas }\end{array}$ & Earnings inequality and in-work-poverty \\
\hline 06/09 & Ramón Peña-Casas & More and Better Jobs \\
\hline 05/09 & $\begin{array}{l}\text { Svenn-Åge Dahl, } \\
\text { Torstein Nesheim, } \\
\text { Karen M. Olsen }\end{array}$ & Quality of Work - concept and measurement \\
\hline 04/09 & $\begin{array}{l}\text { Laura den Dulk, } \\
\text { Bram Peper }\end{array}$ & $\begin{array}{l}\text { Managing work-life policies in the European } \\
\text { workplace }\end{array}$ \\
\hline 02/09 & $\begin{array}{l}\text { Johan Davidsson, } \\
\text { Marek Naczyk }\end{array}$ & The Ins and Outs of Dualisation: A Literature Review \\
\hline $01 / 09$ & $\begin{array}{l}\text { Elke Viebrock, } \\
\text { Jochen Clasen }\end{array}$ & Flexicurity - a state-of-the-art review \\
\hline
\end{tabular}

Working Papers 2008

01/08 Sophie Jacquot

National Welfare State Reforms and the Question of Europeanization: From Impact to Usages

REC-WP

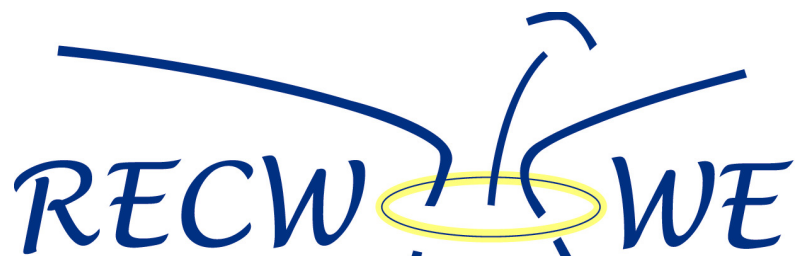

Working Papers on the Reconciliation of Work and Welfare in Europe

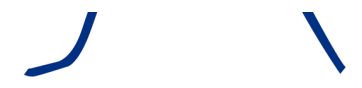

